\title{
MEDICIONES DE ARENA EOLICA EXTRAIDA DE LA PLAYA DE SANTA ROSA POR DEFLACION
}

\author{
Jorge Broggi $\mathrm{R}$. \\ Lima, Peru
}

Por cientos de kilómetros la asfaltovla Panamericana Roosevelt recorre nuestro litoral, sucesión alternada de acantilados rocallosos con otros areno-arcillosos o de grava compacta alternando con playas en su mayor parte o de grava suelta o sea guljarros.

El viento sur dominante, llamado Virazón por los marinos, es poco perceptible en las mañanas y particularmente intenso en las tardes, con ráfagas de velocidades que llegan a pasar $5 \mathrm{~m} / \mathrm{s}$. (metros por segundo), viéndose entonces que extrae la arena seca de las playas para llevarla tierra adentro hasta centenares de metros sobre el nivel del mar, invadiendo en su camino poblados y vías de comunicación con acumulaciones a veces masivas o sea de dunas eblicas, que dificultan y encarecen el transporte y la vida de los pobladores pues caminos, vlas férreas y pueblos quedan parcialmente sepultados en forma tal que solo a fuerza de brazos se logra descubrirlos pues las dunas extienden su pesado manto de muerte y desolación desértica a grandes sectores de nuestra Costa o sea playas y aéreas inmediatas.

A la latitud de lima no es menos visible este panorama que estudiamos en un deseo de encontrar soluciones generales que hagan la actividad humana menos azarosa y se facilite con ello el desarrollo de nuestras vitales industrias. Solucionar el problema de la migración eoloarenose, es pues dar salida segura y barata a los principales productos de nuestro comerclo y facilitar la vida de los transeuntes y poblados en general.

El valor de nuestras observaciones no deja de tener carácter universal, pues al margen de muchos mares y lagos del Orbe, se ofrecen fenómenos similares a los que ocurren en nuestra extensa Costa, siendo muchos los palses que se interesan por eliminar las dificultades que causa el movimiento de las arenas por el viento, porque tal migración afecta donde quiera las actividades del hombre.

Es as1, como observé fenómenos parecidos a los nuestros en la Bahla de Arcachón (Francia) (Golfo de Biscaya) donde quedamos sorprendidos al constatar que paralelamente a la playa se elevaban grandes dunas costeras, que se podlan seguir con algunas soluciones de continuidad por donde la invasión arenose ofrecla un ancho de 3 á 10 kilómetros. All1 el movimiento en masa de las dunas, o transporte masivo, se hace a veces con una velocidad hasta de 30 metros por año amenazando destruir los bosques artificiales de pinos adya- 
COASTAL ENGINEERING

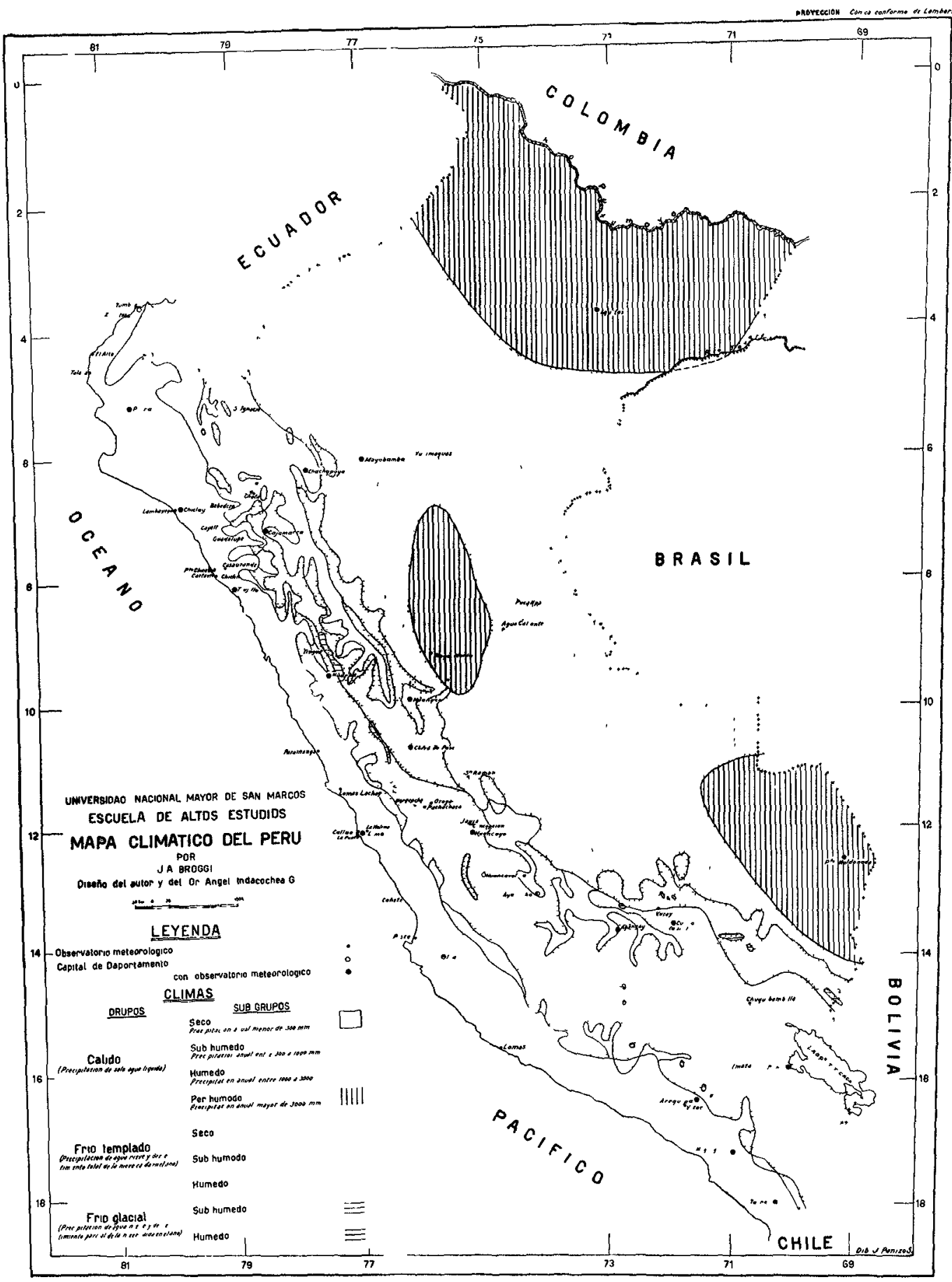

Mapa Climatico del Peru 
centes a la playa y que se han sembrado para ponerle atajo en su avance desolador. (1)

Otra importante área localiza también a lo largo de la Costa Báltica Alemana, donde una pequeña villa fué sepultada por arenas el año 1839 y desenterrada solo en 1869.

No siempre, sin embargo, la migración eoloarenosa en el Continente es totalmente perjudicial, pués como puede verse a 24 kilómetros al sur de Lima (contados de la Plaza de Armas) una industria de ladrillos calcáreos, dá nueva vida a la construcción civil, utilizando como materia prima la arena eólica acumulada en la base del cerro Lomo de Corvina, en la playa de Conchán, entre el Morro Solar y Lurín. También las arenas tienen valor como componente principalmente mecánico de las tierras arables muy arcillosas, al volverlas porosas y airables como desde medio siglo atrás se usan de antideslizante para las locomotoras que trafican en zonas lluviosas andinas, as 1 como material de construcción mezclado a cal y cemento; y por último para filtrar agua y también de abrasivo.

En suma, el estudio que hemos realizado, no solo tiene pues valor cientifico, didáctico, sino eminentemente económico y de aplicación inmediata a la actual cultura en sus diversos aspectos, pues descubre fenómenos antes desconocidos pero que han tenido influencia decisiva en nuestra civilización pretérita y aún la tienen en la actual.

\section{CAPITULO I}

GEOGRAFIA DE LA PLAYA SANTA ROSA

\section{UBICACION E HISTORIA DE IA PIAYA SANTA ROSA}

Esta playa arenosa que ubica al sur de Ancón, es la pequeña parte también meridional de la conocida Playa Grande, de ella separada por un pequeño morro al cual se llama co Santa Rosa; ver en el plano al 20000 publicado por el Instituto Geográfico Militar a base del relevado fotográficamente por el Servicio Aerofotográfico Nacional a solicitud y costo del Instituto Geológico del Perú (véase Anexo No 1, Lám. 1)

La zona que hoy lleva el nombre del Balneario Santa

(1) Sobre este problema y otra de las costas véase: Johnson, Douglas Wilson.- Shore processes and shoreline development, 1st Ed. pp. 584, 1919. 


\section{COASTAL ENGINEERING}

Rosa, ha sido ocupada por el hombre desde los tiempos preincaicos, pués la existencia de extensos y profundos conchales con restos de cocina y cerámica primitiva, lo acredita;pero hace $\tan$ solo 5 años que la empresa particular The Peruvian Trust Company hizo un camino con pavimento de concreto desde la Autovia Panamericana o Roosevelt Norte, tres piscinas, calles, campo de golf $\mathrm{y}$ todo un balneario deportivo.

\section{ACCESIBIIIDAD}

Del km. 36 de la Plaza de Armas de lima siguiendo la actual asfaltovia Roosevelt Norte, sale el ramal pavimentado de concreto de $1000 \mathrm{~m}$. de Iongitud hasta la Playa de Santa Rosa, el que después de ascender $50 \mathrm{~m}$.(verticales) hasta un pequeño portachuelo con arco ojival de concreto a mayor nivel del cual se han instalado tanques de agua potable bombeada desde la margen cultivada del valle de Chillón en Puente Piedra $\mathrm{y}$ baja por el nuevo bảlneario por cerca de $2 \mathrm{~km}$. hasta el mismo Océano Pacifico.

\section{CLIMATOLOGIA}

Según la clasificación termohidrol6gica de J.A.Broggi (1947) la zona se halla en el ärea de Clima Seco (CS) con menos de $300 \mathrm{~mm}$. de precipitación anual de sólo agua líquida que califica normalmente toda nuestra costa desde la frontera con el Ecuador hasta la frontera con Chile.

Ofrecemos como Anexo N22 los cuadros de observaciones meteorológicas realizadas por los técnicos de la ya citada empresa urbanizadora de Santa Rosa y control de la Dirección de Meteorologia del Ministerio de Aeronáutica y que dan idea de algunas particularidades climáticas principales del lugar.

\section{VIENTOS, ARENAS Y DINAMISMO DEL MAR}

Ia aridez del clima de Santa Rosa, los vientos de mar a tierra o virazones, cuyas velocidades al nivel del suelo exeden a veces $5 \mathrm{~m} / \mathrm{s}$ y la existencia de una extensa playa arenosa, son condiciones que favorecen el eolismo o sea un régimen en que la acción mecánica del viento determina la morfología superficial con monticulos de arena o dunas que ascendiendo las cumbres circundantes setentrionales descienden a la conocida Pampa de Ancón.

Dada la predominancia del viento marino, particularmen- 


\section{MEDICIONES DE ARENA EOLICA EXTRAIDA DE LA PLAYA DE SANTA ROSA POR DEFLACION}

te fuerte en las tardes de Noviembre a Mayo, las formas dunáceas revelan en sus sombras y convexidades barcanoides la constancia de su dirección media S-N.

Como Santa Rosa es solo la parte meridional y algo abri. gada de Playa Grande, separada de ella por el Wlorro de ese nombre, el oleaje de alta mar dominante (tumbos) no incide perpendicularmente sino a la parte de la playa situada al $\mathrm{N}$ del Morro lo que significa un oleaje generalmente más reducido en s.lti tiud y violencia en su rompiente de Santa Rosa. Esto no quiere decir que a veces bravezas de origen lejano puedan presentarse siendo particularmente las del NW (ocurrida por ejemplo hace 3 años $y$ que destrozó el rompeolas de piedra cuya construcción se iniciaba en la parte sur de la ensenada de Santa Rosa) las que son más temibles porque no hay abrigo para ellas.

El carácter abierto de la bahía nos dá un régimen norma] de mareas semejante al de casi toda nuestra Costa $\mathrm{C}_{\mathrm{p}}$ tral y cuyas características se conocen, pues se ha determinado su amplitud máxima de sicigias que ocurre dos veces cada 24 horas, y que es de 2.6 piés (1) en el Callao, lo que daría para Santa Rosa cerca de 2.5 piés $\delta$ sea $76.2 \mathrm{~cm}$. de méxima y media anual de solo $57.9 \mathrm{~cm}$.

En lo que respecta a oleaje normal, debemos anotar que el dominante de altamar tiene dirección SSW por lo que al quedar la Playa de Santa Rosa abrigada en parte por el macizo de Piedras Gordas, es sobre todo intenso en Playa Grande, que está más al $N$. donde las olas inciden con una rompiente inicial que frecuentemente pasa de un metro y que con la inclinación media de la playa arenosa de $3^{\circ}$ de lugar a que simultáneamente avancen varias olas rotas y que el área de ella expuesta al viento tenga un promedio de $11 \mathrm{~m}$. de ancho entre alta $\mathrm{y}$ baja mar con oleaje normal.

\section{CAPIIULO II \\ VIENTOS}

DE LOS VIENTOS EN GENERAL

A toda masa de aire en movimiento se le dá el nombre de viento $\mathrm{y}$ de acuerdo con los caracteres de su dinamisno local,

(1) Tablas de mareas.- Ministerio de Narina. República Peruana. Servicio Hidrográfico.- 1958 y 1959. 


\section{COASTAL ENGINEERING}

- clasifica en relación al medio terrestre sobre el cual discurre; pero también es de importancia conocer su temperatura, humedad y sobre todo su caŕacter pulsátil o rafagosidad en relación al transporte élico porque es con las ráfagas que este tiene importancia.

\section{DE LOS VIENTOS EN SANTA ROSA}

Desde tiempo atrás en los observatorios meteorolbgicos se mide solo la dirección de la componente horizontal y velocidad del viento en el aerozocalo o parte inferior de la atmósfera ( $20 \mathrm{M}$. o verticales inferiores) en contacto con la litosfera o la hidrósfera; pero los anotados por la empresa Urbanizadora Santa Rosa (Anexo No 2), omiten sensiblemente su dirección. Con el anemógrafo Lambreth, de que hemos dispuesto por préstamo bondadoso de la Dirección General de Meteorología, se han podido obtener con todo direcciones horizontales en algunos días correspondiente tanto a un punto medio entre la playa y el abra de entrada a la Urbanización, como en el mismo malecón de la playa en los puntos señalados en el plano con las letras M y P.

De una manera general podemos decir que se conoce poco de los vientos en el aerozbcalo peruano y menos en altitud. La Capital de la Republica es el sitio donde se han investigado más; "pero aún falta mucho por conocer de su estructura mecánica detallada" aún de los dominantes en sus 3 M. (inferiores sobre el suelo) que para los efectos de nuestro estudio son los más importantes.

Habiéndose fijado nuestra atención en la estructura fina de este estrato basal, hemos podido observar que los vientos horizontales varian mucho de intensidad en cortos intervalos y que son precisamente los momentos en que su velocidad aumenta o de ráfagas, que el transporte de arena reviste mayor importancia. Es así como se vé con frecuencia en corta fracción de minuto que la arena es transportada en suspensión, o sea flotando en olas, entre las cuales hay periodos hasta de calma casi absoluta de duración mucho mayor.

A este respecto reproducimos el siguiente párrafo de la obra de K. Middleton y Spilhaus (3).

"Besides speed and direction, a third characte-

(3) W.E. Knowles Middleton and Athelstan F. Spilhaus: Meterological Instruments, 3rd. Ed. revised-University of Toronto Press, p. 136, 1953. 
"ristic of the wind is of importance in meteoro"logy. The flow of air over the ground or over "the sea is not smooth, but turbulent: and the "degree of turbulence may be indicated by a quan"tity known as the gustiness. At least six defi"nitions have been suggested for this quantity; "that used by English authors (2) is convenient "for use with the records of many anemometers. "It is

$$
\text { (6.1)...G }=\frac{V \max -V_{\min }}{V_{\text {mean }}}
$$

" The value being taken over a period of 10 minu"tes.

"It is comparatively easy to build an instrument "which will make some sort of record each time "the wind speed changes by one unit (e.g., I mile "per hour). Given such an instrument, a useful "measure of gustiness would be the number of ti"mes per hour that this change takes place. In "symbols

$$
(6.2) \ldots G=\frac{A V}{T}
$$

"Note that the direction of the change does not "matter.............................

"(2) See for example, F.J. Scrase, Geophys Memo"irs No 52 (Iondon Meterological Office 1930)."

El malogrado Dr. Angel Indacochea G., que actuó como Secretario del Comité Geofisico del Año Geofísico Internacional 1957-58, acompañó como asistente a mi señor padre en el problema de medir y estudiar los vientos en nuestra costa con un anemógrafo Lambrecht (Göttingen) que, adaptado a una pequeña torre portátil de acero Dexion de $2 \mathrm{M}$., le dió registros del 17 de Marzo de 1958 al 5 de Abril en la parte central de la Urbanización Santa Rosa (punto $P$ de Láminas del Anexo No 1) y en el Malecón de la misma playa, del 9 al 24 del mismo abril (punto $M$ ). de los cuales obtenemos las siguientes conclusiones:

'1) Ios vientos dominantes en todo el sector de Santa Rosa vecino a la playa, son del S con desviación al SW durante las tardes en que su intensidad aumenta $y$ al SE por las noches en que disminuye. 


\section{COASTAL ENGINEERING}

2) Las mayores velocidades, se han registrado después del medio día hasta el anochecer con ráfagas hasta de $25 \mathrm{~m} / \mathrm{s}$ y por pocos segundos solamente.

3) Desde la media noche, las velocidades son generalmente minimas y del SE, llegando hasta la calma absoluta a las 9 ó 10 de la mañana en que comienza a soplar el viento del SW.

4) Con la modificación del anemógrafo Lambreth a velocidades de giro del tambor registrador diez veces mayor que la de fábrica, se obtuvo, en períodos de más de tres minutos de duración total, promedios hasta de $10 \mathrm{~m} / \mathrm{s}$ durante los cuales se anotaron picos de $25 \mathrm{~m} / \mathrm{s}$.

Las ráfagas diurnas fueron visiblemente acompañadas de fuerte migración arenosa en la playa y a no más de $25 \mathrm{~cm}$. de altura, que tierra adentro excedía de un metro cuando la turbulencia crecía y se produclan visibles remolinos.

Los registros de la playa (M=malecón), rara vez tuvieron picos de $10 \mathrm{~m} / \mathrm{s}$; pero en los sitios de mayor altitud, las ráfagas pasaron con frecuencia de esa velocidad.

5) Por fuerte transporte salino (por atomización del agua de mar), tuvo que eliminarse previamente por barbotaje en agua pues la sal marina en suspensión en aire que ingresaba al anemógrafo obstruf́a el instrumento.

De todo esto se deduce, que es de gran valor continuar las investigaciones de rafagosidad, estudios que deben extenderse a la superficie del mar y continente adentro, pues tan pronto como en los desiertos produce fuerte acarreo de arena origina en el mar corrientes superficiales y de fondo, que tie. nen gran importancia como transportadora de sedimentos. En

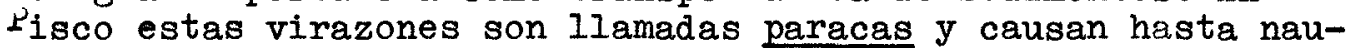
fragios de pequeñas embarcaciones a vela y notable acarreo de polvo y arena por decenas de kilómetros.

Como no se ha observado estrecha relación entre las diferencias de temperaturas de mar y tierra con los vientos, como entre la dirección de estos y la línea de playa o sea su angularidad, creo que se impone un estudio más profundo de las virazones 0 vientos dominantes del mar (S y SW). Se ha podido constatar, con todo que las virazones son más intensas cuando desaparece el conocido "banco de nubes", lo que se explica porque estos estratos bajos son barridos por vientos originados en capas altas de la atmósfera. 


\section{MEDICIONES DE ARENA EOLICA EXTRAIDA DE LA PLAYA DE SANTA ROSA POR DEFLACION}

\section{CAPITULO III}

\section{ARENAS}

Definición.- Entre los sedimentos acuosos o sea depósitos granulares con poca adherencia entre sus partículas, está la arena, cuya definición y diferenciación se hace por las dimensiones de sus granos que varlan, según la mayor parte de los gé́logos y petrólogos, entre diámetros de $2.5 \mathrm{~mm}$. y $0.05 \mathrm{~mm}$. (4)

Origen.- Por su constitución de fragmentos cristalinos se puede decir que derivan de la desintegración de rocas de tal carácter, pudiéndose afirmar que primariamente lo son de Igneas o metamórficas, pero que también pueden provenir de sedimentarias particularmente detriticas poco cementadas. $\mathrm{Mu}-$ chos autores creen que al hallarse en las playas fuertes acumulaciones, las arenas se forman on las rompientes como resultado del embate de sus aguas sobre las rocas o fragmentos rocosos de las orillas; pero tan solo se puede ver trituración cuando el oleaje desmenuza las conchas adheridas a peñascos. Por felicidad ya son pues pocos los gélogos que consideran esta acción mecánica como la causante principal de su formación.

Es evidente que las arenas se producen principalmente por la acción fisicoquímica primera del intemperismo atmosférico, que desintegra los elementos cristalinos de las rocas cuya resistencia es muy variable dando como resultado un se dimento granular incipiente. Ias aguas de escorrentia transportan después sus granos, en un principio angulosos y más tarde de aristas redondeadas, hasta el mar en donde se verifica su transporte con selección dimensional simultánea por corrientes marinas de fondo para ser llevadas a las rompientes y formar playas arenosas o sea acrecencias continentales con terrazas playeras a nivel superior a las de las más altas mareas.

De las arenas playeras y eblicas en general.- Bastante diferente es el comportamiento fisicoquimico de un grano de arena bajo el agua que bajo el aire; pero cabe, a primera vista, distinguir el mecánico, pues al tener que yacer en un medio cuya densidad se aproxima a la propia, su resistencia al movimiento del flúido en que yace, tiene que ser menor que ba-

(4) Véase p. ej: F.H. Lahee: Field Geology p. 34 y siguientes. Ed. 1941 como W.C. Krumbein and Pettijohn: Manual of Sedimentary Petrography. 


\section{COASTAL ENGINEERING}

jo la atmósfera cuya densidad es relativamente pequeña.

Siendo la playa la parte de la litósfera que sufre la periódica invasión del agua de las rompientes, los granos de arena que a ella convergen del mar o del continente, tienen que estar sujetos a un cambio constante de medio y por lo tanto de adhesión a granos colindantes. Una arena húmeda bajo el agua es diferente que bajo el aire. En ambos casos el flúido se interpone entre sus granos, pero dá a la arena propiedades distintas. Complejo es el caso de que esta impregnación de agua de mar, por ejemplo, esté en proceso de desaparecer por evaporación en la atmósfera libre, pues entonces se produce la adherencia de sus granos no solo por el agua sino por los sólidos que tiene en solución. Estas arenas no son pues propiamente eólicas sino están secas, proceso que lento y varía con el viento, temperatura y humedad del ambiente subaéreo $\tan$ tornadizo.

Secas o casi tales, las arenas playeras están entonces constantemente expuestas a la deflación o sea al fenómeno geomorfológico de desgaste en masa por el viento que constantemente se lleva sus granos superficiales y en proceso dinámico ocupa áreas netamente continentales.

Las playas de Santa Rosa y vecinas, nos muestran estos fenómenos, que pueden $\mathrm{y}$ deben ser objeto de una investigación fisicoquímica más exhaustiva.

Las arenas eólicas, entendiéndose por tales las que aparentemente no poseen adherencia entre sus granos por tener sus poros ocupados solamente por aire, se extienden pues a casi la totalidad de nuestra Costa, excepción de su extremidad norte donde la precipitación atmosférica es considerable (Tumbes). Su coloración de tierra es general en grandes masas, siendo oscura cuando dominan los granos de magnetita y clara cuando lo hacen feldespatos o el cuarzo lechoso. En lo que respecta a dimensiones de granos diremos que son de grano grueso cuando están en áreas abiertas donde los vientos son fuertes; y fino, o sea casi loess, cuando los vientos son solo débiles como en las quebraditas abrigadas y en la parte de la zona climática de Lomas al llegar a las altitudes máximas de invasión de las virazones.

En Santa Rosa y Playa Grande las arenas cubren siempre las pendientes que miran al mar hasta transmontar las cumbres que no exceden $300 \mathrm{M}$ y Ilegar continente adentro, a altitudes en donde domina el "Banco de stratus de la Costa" que cubre las"Lomas" en envierno y buena parte del otoño y primavera. 


\section{MEDICIONES DE ARENA EOLICA EXTRAIDA DE LA PLAYA DE SANTA ROSA POR DEFLACION}

Ia humedad salina de las vecindades del mar, solo permite en la playa el crecimiento espontáneo de una que otra planta de hojas carnosas como de sesuvium y más lejos, de las resistentes tillandsias y musgos con cactáceas (5). Es esta la vegetación espontánea más visible. La irrigación con aguas dulces, al disolver el cloruro de sodio, favorece el crecimiento de vegetación netamente continental. Como las arenas son originadas mayormente por la desintegración de las rocas granodioriticas de las vertientes occidentales de los Andes (6) y llevadas al océano para migrar en buena parte hacia las playas por corrientes marinas de fondo y de alli, por las virazones, volver al continente en ciclo cerrado que tiene por teatro el litoral, no se diferencian mucho en su naturaleza mineralógica y solamente se nota cierta selección dimensional como resultado de la acción mecánica clasificadora de los flúidos que la transportan según su velocidad.

En apoyo de esta afirmación, podríamos transcribir la que expresa el destacado geólogo suizo Amstutz (7) profesor en Rolla, Missouri, en una última contribución sobre "Las arenas de las barcadas del Sur del Perú", en que ya menciona a mi señor padre (J.A. Broggi. 1952) en estudio anterior suyo sobre su origen en las rocas granodioriticas del superbatolito Circumpaclfico. Dice asi:

"The mineralogic composition is: quartz, some "felspar and some biotite, augite and hornblende. "The percentage of these minerals changes from "one barchan to the nex and also from one part of the "barchan to another part. Crests of secondary wa"ves are often darker, containing a larger number "of dark minerals or $(i)$ exhibiting a horizontal "lineation of the dark platy or lathy minerals, "whereas the valleys are lighter, due to less ma"fics or $(i)$ a vertical orientation of the mafics. "The sands most probably originated from granites "and decitic volcanics outcropping at the southern "of the desert".

(5) Weberbauer, A.- El Mundo Vegetal de los Andes Peruanos, pp. 776, 1945 .

(6) Broggi, J.A.- Migración de las Arenas a lo largo de la Costa Peruana, pp. 25, separata de Bol. Soc. Geol. del Perú. T. XXIV (Vol. Unico). 1952.

(7) Amstutz G.C. y Raimundo Chico.- Sand size fraction of South Peruvian barchans and a brief review of the genetic grain shape funtion; separata of Bull. Ver. Schwelzer Pe trol Geol. u Ing. Vol. 24,Nr 67, S 47-52, Fig. 28, February 1958. 


\section{COASTAL ENGINEERING}

Aunque la poca variabilidad de constitución mineralogica de las arenas, no ha estimulado su análisis mineralógico detallado, Io dicho por Amstutz es suficiente para reconocerla a grandes líneas.

El peso especifico de las arenas varía además bastante, siendo mayor cuando está húmeda (8). Ia arena de las barcanas es superficialmente más húmeda con el roclo de las mafranas, desecándose a medida que el sol y el viento se intensifican. Cuando está húmeda es algo coherente, coherencia que se pierde con su desecación al viento y sol.

Ia constitución granular de dos muestras de arena eólica recogidas en un frasco de boca ancha, colocado en el suelo y contra el viento por mi sefior padre en 1952, en la playa de Santa Rosa, y analizadas en el laboratorio del Cuerpo de Ingenieros de Minas, por el químico Walter A. Solis, fué la siguiente:

\section{ANAIISIS GRANULOMETRICO}

\begin{tabular}{|c|c|c|c|c|c|c|}
\hline \multicolumn{2}{|r|}{ Muestra } & No & 1 & \multicolumn{3}{|c|}{$N^{\circ} \quad 2$} \\
\hline $\begin{array}{l}\text { Malla } \\
\text { No }^{\circ}\end{array}$ & $\begin{array}{l}\text { Lado de la } \\
\text { malla en } \mathrm{mm} .\end{array}$ & $\underset{\%}{\operatorname{Parcial}}$ & Acumulado & & $\begin{array}{r}\mathrm{Pe} \\
\text { Ircial }\end{array}$ & Acumula \\
\hline$+\quad 48$ & 0.295 & $-\quad 17.1$ & 17.1 & -- & 0.1 & 0.1 \\
\hline+65 & 0.208 & $=\quad 35.0$ & 49.0 & -- & 9.7 & 9.8 \\
\hline+100 & 0.147 & $-\quad 20.4$ & 69.4 & -- & 38.2 & 48.0 \\
\hline+.150 & 0.104 & 24.7 & 94.1 & - & 47.4 & 95.4 \\
\hline+200 & 0.074 & 4.7 & 98.8 & - & 4.1 & 99.5 \\
\hline-200 & 0.074 & 1.2 & 100.0 & - & 0.5 & 100.0 \\
\hline
\end{tabular}

(8) En experiencia de laboratorio con arena desecada de Santa Rosa, hemos observado un incremento de volúmen de solo $1.85 \%$ por $25 \%$ de peso cuando se satura de agua o sea un incremento de peso especlfico de más de una quinta parte. 


\section{MEDICIONES DE ARENA EOLICA EXTRAIDA DE LA PLAYA DE SANTA ROSA POR DEFLACION}

Un promedio de la constitución química según análisis del mismo químico, fué:

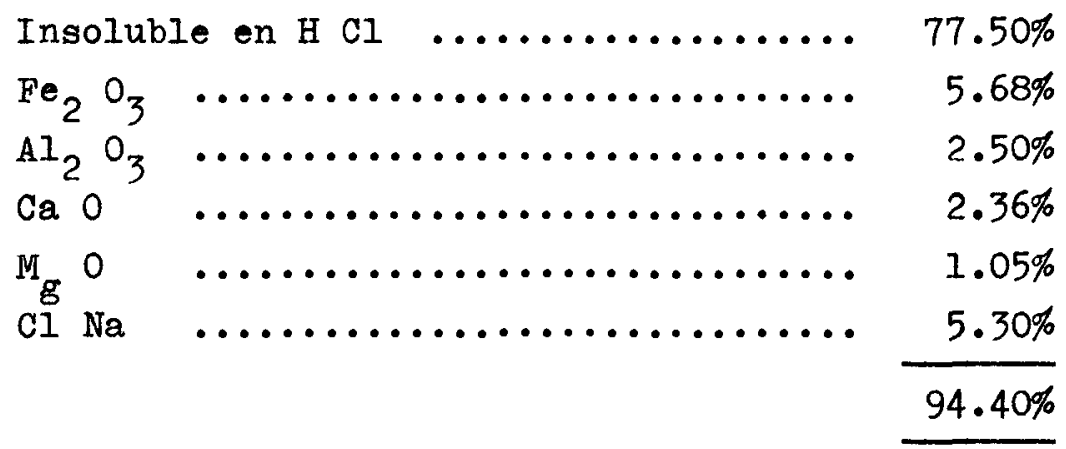

\section{CAPITULO IV}

TRANSPORTE DE ARENAS POR EL VIENTO

Del transporte de arenas por flúidos en general.- El transporte por el viento no es sino un caso particular del transporte por los flúidos, sobre los cuales la bibliografía es muy nutrita, tanto en la parte teórica como experimental. Con todo el problema es tan complejo, que falta aún mucho por conocer.

Recomendamos por hoy las obras clásicas de Bagnold (9) sobre Neumodinámica y de Rubey (10) Hjulström (11) sobre Hidrodinámica. Ambas dejan ver las complicaciones del movimiento de flúidos en movimiento sobre sólidos fragmentados. "Bourdary Layer" "Bottom Layer" son vocablos aplicados a la zona limítrofe entrambos, en la cual tanto las partículas del flúido como del sólido tienen movimientos complicados como son los laminares y turbulentos en caso de líquidos y de arrastre, rodamiento, saltación y flotación de gases como el aire. Bagnold da énfasis a la saltacion, la que a nuestro modo de ver se produce solo cuando hay turbulencia del flúido.

(9) Bagnold. R.A.- The physics of blown sand and desert dunes: 1941. Reprinted 1954.

(10)Rubey, william $W .-$ The force required to move particles on a stream bed. U.S. Geological Survey. Professional Paper 189 - Ed. 1938.

(11)Hjulstrơm o Hjulstroem, Filip; Bull. Geological Institution of University of Upsala. Vol. XXV, pp. 223-525,193435. 


\section{Hjulstrơm dice: (op. Cit. p. 328)}

"The current and other physical conditions prevailing "in the lowest zone of a river, are extremely compli"cated, and have defied every effort to make a fairly

"exact description. They are presumebly very variable.

$Y$ mas adelante (p. 331-332), al tratar del transporte, dice:

"A factor that renders it more difficult to understand "the conditions in the bottomlayer and also the velo"city distribution a.s well as the whole transportation "of solid material, is the imperfect knowledge of "transportations mechanics.- The writer has previously "made a difference between the transportation of bed"load and suspended material, and in Chanter II transi"tion stage, saltation, has been mentioned. The trans"portation of the bed-load may, however, be effected "In still more way.

"GILBERT (1914) has further explained these ways in "his admirable book on transportation of debris by "running water. He at first makes a difference between "movement of individual particles and collective move"ment. In the movement of individual particles "sliding" "is a negligible factor. The roughness of the bed cau"ses particles that retain contact to roll - Rolling "is the mere prelude to saltation". (op. cit. p. 26). "Saltation or jumping was caused by the hydrodynamic "upthrust, but of course the vertical velocities of "the turbulence are also rather important at least in "the topleyer of the saltation zone where a transi"tion to suspended matter exists.

"Individual particles in bed-load thus move in one "of the following ways:

1. sliding

2. rolling

3. saltation

" Transportation by rolling may casily he effected "without saltation, especially of mixed debris. On the "other hand saltation would not appear usual otherwise "than in connection with the transition state, rolling. " There is perhaps more of a graduation difference "than a species diference between the transportation "states mentioned. And also when sliding and rolling "the grans are forced to lose contact with the bed for 


\section{MEDICIONES DE ARENA EOLICA EXTRAIDA DE LA PLAYA DE SANTA ROSA POR DEFLACION}

"very short distances; these little jumps increa-
"sing in length, we get a transition to saltation".

Se deja pues comprender la falta de conocimiento fundamental sobre jas energías puestas en juego para la traslación de cada grano de arena desde sus lugares de reposo.

Krumbein y Pettijohn (12) expresan además:

"One of the fundamental principles on which mecha"nical analysis is based, is that small particles "will settle with a constant velocity in water or "other fluids. It is universally true that small "particles reach this constant velocity in a fluid "medium as soon as the resistance of the fluid "exactly equals the downward constant force (gravi"ty) which acts on the particles. In general the "settling velocity of the particle depends on its "radius, its shape, its density, its surface textu"re, and the density and viscosity of the fluid. A "number of mathematical expressions have been deve"loped to show the relations among these factors "some based on empirical grounds and others on theo"retical grounds. Several of these laws will be "discused in varying detail, depending upon their "applicability in mechanical analysis".

Pero tratándose de la traslación eólica de varias particulas de arena y no de una sola, cabe agregar otro factor no mencionado por los tratadistas, tal es el de incorporación en ellas de líquido que le dá adhesión o coherencia a sus granos. En el caso de las arenas y el agua, este penetra en sus poros y actua como de débil cemento, por lo que es bien visible el diferente comportamiento en masa, cuando húmedas o secas, pues la mayor o menor humedad que las impregna es factor decisivo en disminuir o aumentar su migración. Cuando saturadas, se comportan pues más como conglomerado granular que como sedimento detrítico o sea más como un arenisca que como simple arena suelta (é́lica).

La forma como se acomodan los granos de arena al sedimentarse, tiene también influencia aparte de su forma individual. Experiencias realizadas er $l$ laboratorio por mi señor padre, muestran que al dejar caer arena suelta dentro de una probeta, su volumen se reduce en un $10 \%$ al sacudirla suavemente

(12) Krumbein E Pettijohn - Mannual of Sedimentary Petrography, p. $95 ; 1938$. 


\section{COASTAL ENGINEERING}

por algunos segundos debido al más estable acomodo de sus granos.

De otro lado, cuando el aire discurre sobre una superficie rugosa como es la de una masa de arena, en el lecho de base se produce una turbulencia microscópica ha sido poco o nada estudiada; pero por lo que se observa en la migración de masas de aire en los desiertos relativamente planos, el mismo incremento de velocidad del viento les dá poder ascencional de sólidos o líquidos sobre los que discurre. En menor escala tal cosa debe ocurrir también cuando el movimiento es aparentemente laminar.

De todo Io dicho, se infiere la complejidad del fenómeno físico de migración de las arenas por dinamismo de los flúidos que discurren sobre ellas, en mayor proporción cuando se trata del aire cuya movilidad molecular es tan grande en relación al agua.

\section{CAPITULO V}

\section{MEDIDA DEL TRANSPORTE DE ARENAS POR EL VIENTO}

Introducción.- Dada la complejidad del transporte élico y las grandes dimensiones del ambiente geológico en que tiene lugar en los continentes, la medida integral de la cantidad de arena transportada por el viento es difícil de lograr con exactitud, pues o bien el lecho de fondo en la superficie del suelo se desliza por arrastre y rotación cuando el viento es muy suave, como puede ser llevado saltando y flotando en el aire. En ambos casos extremos escapa a la observación y mensura instrumental en buena proporción.

Sin embargo, como en nuestra costa es visible que nuestros vientos rara vez lleguen a velocidades mayores de $10 \mathrm{~m} / \mathrm{s}$. el transporte se hace normalmente flotando o saltando a alturas de no más de pocos centímetros sobre el suelo con simultáneo arrastre y rotación por el suelo. Como aparentemente casi la totalidad tiene lugar por baja saltación y flotación, en nuestro deseo de llegar a conclusiones numericas de valor, siguiendo las indicalciones de mi Sr. Padre y su técnica para tal fín, acometimos en Santa Rosa la tarea de medir la cantidad de arena extraida por el viento en esa playa de egresión arenosa (13) más como un medio de evidenciar tal fenómeno que

(13) Broggi.J.A.- Op.cit., 1952 


\section{MEDICIONES DE ARENA EOLICA EXTRAIDA DE LA PLAYA DE SANTA ROSA POR DEFLACION}

de Ilegar a obtener guarismos precisos de las masas transportadas puesto la escasez de recursos económicos de que dispusimos hizo incompletas nuestras investigaciones.

A lo largo de nuestra Costa, la egresión arenosa eólica de la gran mayoría de playas, es un fenómeno evidente. Extensas áreas arenosas, casi planas, frente al mar como las de Conchán. Playa Grande y Ventanilla en las proximidades de Iima y a un nivel de solo pocos centímetros sobre el de las más altas rompientes (salvo del oleaje de maremotos y muy grandes bravezas) no tienen otra explicación. En esas áreas, se originan lo que mi padre ha designado chiflones arenosos (14) o sea cadenas o cursos alargados de barcanas que por kilómetros ascienden y descienden las bajas estribaciones andinas obedeciendo al dominante viento Sur Ilamado virazón. Son pues el equiverso de los pótamos, que por gravedad van de arriba hacia abajo; y si bien es difícil estimar numéricamente el transporte integral de sedimentos acuosos por dificultad de conocer a fondo las modalidades de su transporte, cuando más no ha de ser el producido por un flúido tan liviano como el aire, cuyas corrientes llenas de turbulencia varían tanto horizontal como verticalmente a través del tiempo, llevando los sedimentos finos de abajo hacia arriba.

La apreciación geológica integral subjetiva, tan sugerente, llevó a mi Sr. Padre a obtener una apreciación cualitativa del eolismo en las costas desérticas arenosas de nuestro país; pero en esta tésis, usando su técnica e instrumental en Santa Rosa, hemos logrado los resultados cuantitativos que pasamos a exponer.

Arenómetros.- Por varios años y persiguiendo mi Padre la mensura de la cantidad de arena transportada por el viento, diseñó instrumentos sencillos que llamó arenómetros.

El principio físico en que se fundan, es el de provocar la sedimentación o caĺda por gravedad de los sólidos en suspensión o saltación en el aire, mediante la intercepción de un receptánculo sin escape que obligue al aire a estar en reposo. Esto lo obturo mediante vasijas con una sola abertura o boca, en cuyo interior era visible la deposición de la arena eólica en el colchón de aire de su fondo en condiciones de ser pesada. Después de varias experiencias, logró decidirse por Ios ordinarios tubos de prueba inclinados $45^{\circ}$, los que colocados boca al viento, no solo dejaban entrar la arena flotante sino la que saltaba. La que se arrastraba o rodaba era imposi-

(14) Broggi.J.A.- Op. cit. p. 10 


\section{COASTAL ENGINEERING}

ble medirla; pero es aparente que solo en débil porcentaje escapaba a la mensura pues llegaba a saltar y flotar con la acción continuada del viento.

Aunque en un principio mi padre usó un tubo de prueba, la necesidad de conocer la migración en altitud sobre el suelo con algún detalle, lo llevó al diseño de los arenómetros que denomino de Zbcalo (BZ) y de Altitud (BH) que se muestran en el Anexo $N^{\circ} 3$. Consistían ambos en una superposición de tubos de prueba en contacto en el BZ y separados a distancia no menor de $10 \mathrm{~cm}$. en el $\mathrm{BH}$. En la práctica se observó que solo cuando el nivel de la arena en el interior de cada tubo pasaba de $1 \mathrm{~cm}$. de la boca, la turbulencia la extraía hacia afuera; de otro modo quedaba inmóvil en su interıor.

Como cuando las velocidades del viento que exceden de $5 \mathrm{~m} / \mathrm{s}$. es visible la saltación y suspensión de los granos de arena y tal velocidad adquiere el viento cuando discurre más fácilmente sobre las pistas asfaltadas en donde la fricción de las capas del flúido con el piso disminuye, se ven entonces con claridad sobre el fondo negro del asfalto las trayectorias que siguen los granos que flotan y que nunca son líneas rectas horizontales o verticales, sino irregulares y más bien helicoidales con ángulo de tangencia de $5^{\circ}$ a $10^{\circ}$ solamente con sus ejes o sea hélices muy alargadas y de eje también curvilíneo irregular. Con estas trayectorias los granos de arena entran fácilmente a los tubos de los arenómetros cayento en su fondo. Como la base de todo arenómetro se coloca horizontalmente en la arena del suelo y los tubos orientados a sus rizaduras, se logra recoger en ellos la mayor parte de la arena visiblemente transportada por flotación y también entra la que salta.

Con el fin de que el arenometro recoja al máximo la arena que salta, se ha procurado que la del suelo cubra su soporte-base hasta un nivel medio tangente inferior a la boca del tubo más bajo del arenómetro, lo que se logra excavando en el suelo arenoso algo ondulado la depresión consiguiente. El Anexo № 3 exhibe fotos de dicho arenómetro en acción en Santa Rosa.

Como entre tangente $\mathrm{y}$ tangente inferior hay un desnivel de una boca de tubo hay un desnivel de $2.12 \mathrm{~cm}$. en el arenómetro BZ (Broggi de Zocalo) el tubo No 2 queda a esta altura sobre el suelosi el No 1 es tangente a él.

Con el fin de obtener datos numéricos del transporte en altitud mayor, es que construyó mi padre el arenómetro de $2 \mathrm{~m}$. que llamó BH o de Altitud, con huecos cada $10 \mathrm{~cm}$. para colo- 


\section{MEDICIONES DE ARENA EOLICA EXTRAIDA DE LA PLAYA DE SANTA ROSA POR DEFLACION}

car en ellos los tubos de prueba inclinados 450 como se ve en fotos del mismo inexo 3 .

Estimaciones.- Después de haber colocado los arenómetros el tiempo adecuado bocas libres al viento, se retiraron cubriendo los tubos con los mismos tapones de jebe provistos de las numeraciones necesarias para reconocerlos al ser pesados sus contenidos arenosos en el laboratorio.

Muy conveniente es conocer la proyección, en plano vertical, de la boca de cada tubo, puesto que consideramos en promedio horizontales las trayectorias de los granos de arena que saltan o flotan en el aire, constituye dicha proyección la superficie efectiva de captación o ingreso al tubo. Fácil es ver, en las ilustraciones del arenbmetro BZ, que esta proyección es ellptica con el eje mayor igual al diámetro del tubo y área de $93.83 \mathrm{~mm}^{2}$ o sea detl $\mathrm{cm}^{2}$ en cifras redondas. In el Anexo 6 se exhiben los cálculos sencillos que nos llevan a este resultado.

Mensura del transporte eoloarenoso en general.- Las experiencias con arenometros BZ, las podemos agrupar en 3 tipos reveladores de las modalidades de la extracción (egresión) y transporte de arena por el viento en la playa de Santa Rosa que son:

1) Experimentos con un solo arenómetro BZ, expuestos en orden de fechas (4nexo 4)

2) Ixperimentos con 3 y 4 B\% en linea paralela a la rompiente en orden de fechas (4nexo 5)

Estos experimentos se pueden considerar como preliminares pero son los suficientemente precisos para arrojar evidencias indiscutibles que constituyen la escencia de esta tésis.

Los del primer grupo, 8 en total. (snexo 4), son experimentos individuales: 2 en Enero, 2 en Febrero, 2 en Marzo y 2 en $\mathrm{Abril}$ de 1958. Como los Instrumentos destinados a medir el viento regional ( $X$ ) se trasladaron en Febrero de un costado de la Piscina Grande de la Playa de Santa Rosa, al abra de entrada de la Urbanización, no hay datos de ese mes; pero en

(X) Instrumentos suministrados por la Dirección General de Meteorología correspondientes a estaciones de segunda categoría cuyo manejo dejo bastante que desear como se constata por las fallas de observación de snexo 2. 
Ios dos días de Enero los experimentos se realizaron cuando el viento regional, considerando ráfagas, era de 6 a $8 \mathrm{~m} / \mathrm{s}$ (véase Anexo 2: Observaciones Meteorológicas en Santa Rosa). Las mediciones más precisas hechas con anemómetros Fuess a $1.6 \mathrm{~m}$. sobre el suelo al lado de los arenómetros, revelaron que el viento fué más fuerte en el Experimento I que en el II, 10 que es visible también en el mayor peso recogido de arena a casi iguales alturas en los tubos 2 y 364 y 5 de Ios arenómetros de ambos experimentos.

En Febrero la mayor cantidad de arena recogida en el Experimento III con relación al IV fué también resultado de la mayor velocidad del viento, pero tambien de la mayor distancia del arenómetro a la línea mojada de playa $(30 \mathrm{~m}$. en vez de $10 \mathrm{~m}$.$) , 10$ que permitió mayor área seca de extracción de arena por el viento y cuyo ancho podemos asimilarlo al fetch oceanográfico denominándolo fetch eoloarenoso.

De lo realizado en las 4 primeras experiencias individuales con BZ y confirmado por los 4 siguientes, se puede pues colegir:

a) que con vientos regionales fuertes, el acarreo de arena es mayor

b) que cuando es mayor la amplitud de arena seca en la playa o fetch eoloarenoso, es mayor la cantidad de ella extraída por el viento.

c) que cuando es mayor ese fetch eoloarenoso se forman rizaduras (ripple marks) y mayor es tambien el acarreo de arena en altitud.

Determinadas las causas de variación en un punto, nos dedicamos a medirla simultáneamente en otros puntos de la playa, en posición paralela a la rompiente, con los resultados que consignamos a continuación:

Variaciones horizontales del transporte eoloarenoso.- Con la finalidad de conocer las variaciones del transporte en frente horizontal y altura del zócalo eoloarenoso, usamos de observaciones simultáneas hasta con 4 arenómetros $\mathrm{BZ}$, las que forman parte del Anexo No 5, que consigna primeramente los resultados del Experimento No I con 3 arenómetros expuestos casi simultáneamente durante el mismo lapso a $10 \mathrm{~m}$. de la línea húmeda de playa o sea con $+10 \mathrm{~m}$. de fetch nunca cubierto por el agua del mar durante el periodo de la experiencia a $30 \mathrm{~m}$. uno de otro. Este experimento se hizo el 26 de febrero de 1958 y como se puede notar en el arenómetro No 2 o intermedio, la cantidad de arena recogida fué casi la mitad de las No I y 3 . 


\section{MEDICIONES DE ARENA EOLICA EXTRAIDA DE LA PLAYA DE SANTA ROSA POR DEFLACION}

Los tubos 7 - 12 no recogieron sino trazas. Esto revela tal vez que la velocidad promedio del viento también era variable en frente horizontal.

Las pequeñas diferencias de tiempo de pocos minutos en los INICIOS $Y$ TERMINOS, se deben a que no hubo ayuda para cubrir y descubrir los tubos de los arenómetros con simultaneidad.

Con el fín de comprobar estas variaciones horizontales, el 28 de Marzo de 1958 colocamos otros tres arenómetros BZ a lo largo de la playa: el No 1 , donde realizamos el Experimento I del Anexo 4 o sea bajando la escalinata de la vereda que conduce a la playa (Anexo 3) inmediatamente a pocos metros al sur; el No $2100 \mathrm{~m}$. más al $\mathrm{S}$ y el No 3 a $150 \mathrm{~m}$.más lejos ó sea el extremo meridional de la pequeña caleta de Santa Rosa, los 3 á $20 \mathrm{~m}$. de la línea húmeda de playa. Los resultados se indican en los cuadros respectivos del Anexo No 5 . Como se trata de operaciones simultáneas, quedó demostrada la variabilidad tanto en línea horizontal como vertical del transporte eoaloarenoso en el aerozócalo, pues la observación duró cerca de 6 horas. En dicho anexo consignamos el anemograma obtenido con Anemógrafo Lambrecht en las horas de observación $(x)$.

Otro Experimento realicé el 9 de Abril con 4 arenómetros BZ distantes 30 metros entre ellos y a $15 \mathrm{~m}$. de la línea mojada de al ta marea del día (Experimento III, Anexo No 5). Entre los arenómetros 2 y 3 (siendo el l el más próximo a la escalinata de bajada a la playa), se midió la velocidad del viento a $15 \mathrm{~cm}$. sobre el suelo con anemómetros de precisión, obteniéndose:

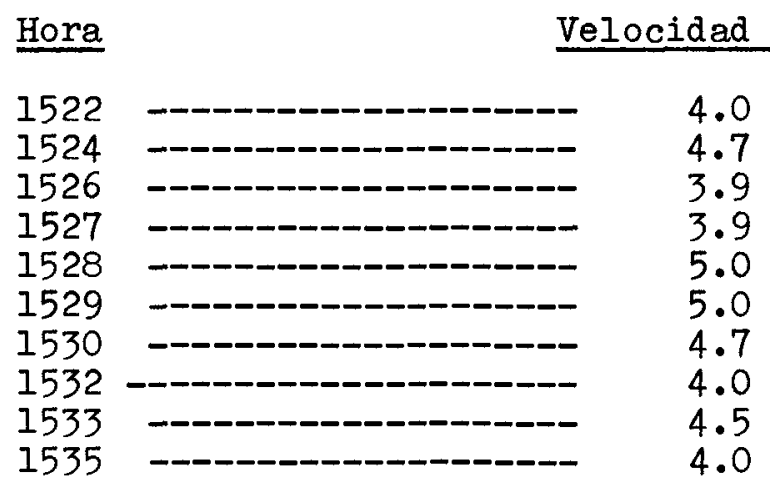

(x) Estos experimentos fueron realizados por el malogrado Dr. Angel Indacochea G., en el punto $\mathrm{P}$ del plano al 20000 del Anexo No 1. 


\section{COASTAL ENGINEERING}

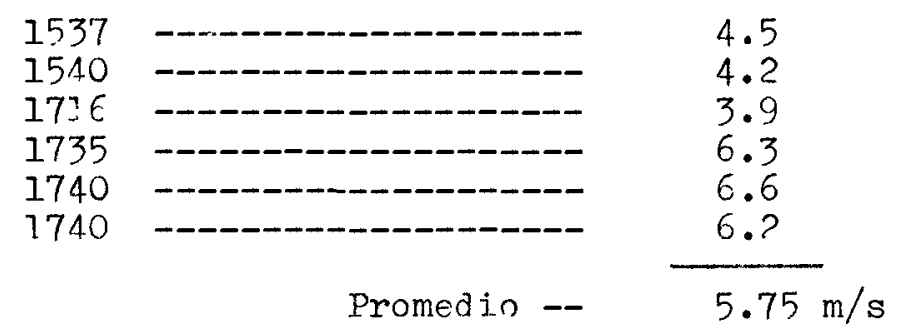

Con el Experimento IV, colocando ? arenómetros a $50 \mathrm{~m}$. uno de otro y a $10 \mathrm{~m}$. de la línea mojada de alta marea, se obtuvieron los guarismos respectivos de]. Anexo 5. Hil Arenómetro No 2 estuvo colocado a solo $40 \mathrm{~m}$. al $\mathrm{S}$ del término de la escalinata ya mencionada $y$ ambos revelaron que al norte de la playa el viento y transporte arenoso era más intenso, 10 que se podía comprobar por simple observación visual.

Dos arenómetros $\mathrm{BZ}$ fueron nuevamente colocados el 12 de abril en los mismos lugares de la playa, día que tuvo caracteres de insolación semejantes al 10 pero con el viento más fuerte, obteniéndose los dos últimos registros del Anexo No 5. Como un solo tubo de prueba y hasta solo $1.3 \mathrm{~cm}$. de la boca se pudo recibir $33 \mathrm{gm}$. de arena, en los registros respectivos el tubo 1 cuya boca estaba al nivel medio del suelo resultó pues casi lleno de arena.

Medida la inclinación media de la playa Santa Rosa entre la baja y alta marea, resultó ser en promedio de $3^{\circ}$.

Variaciones verticales del transporte eoloarenoso.- Hasta aqui las variaciones del transporte en altitud observables en los registros de los Experimentos (Anexo 4 y 5), no habían pasado del zócalo o sea la altura de los tubos de tal arenómetro ( $+25 \mathrm{~cm}$.$) pudiéndose solo observar pequeñas anomalías$ consistentes en inversiones poco saltantes de la gradiente de decrecimiento de los pesos de arena en altitud; pero deseosos de conocer estas más arriba, hicimos uso del arenómetro $B H$ de $2 \mathrm{~m}$. con tubos separados $10 \mathrm{~cm}$. de otro, con la misma inclinación de $45^{\circ}$ (Anexo 6). Un BH fué colocado fijo a uno de los postes chicos de la parte más meridional de la antena radial existente en el Minitrack de la Pampa de Ancón y dejado por 33 días, desde el 8 de marzo hasta el 10 de abril de 1958, dió desde el tubo inferior con boca a $5 \mathrm{~cm}$. sobre el suelo, los siguientes pesos de arena depositada en tubos distanciados verticalmente $20 \mathrm{~cm}$. los más bajos y solo $10 \mathrm{~cm}$. los 3 más altos o sea los $10,11 \mathrm{y} 12$. 


\section{MEDICIONES DE ARENA EOLICA EXTRAIDA DE LA PLAYA DE SANTA ROSA POR DEFLACION}

$\begin{aligned} \text { Tubo No Peso de arena } & \begin{array}{l}\text { Altura sobre el suelo de } \\ \text { mg }\end{array} \\ & \text { la tangente inferior a la } \\ & \text { boca del tubo }\end{aligned}$

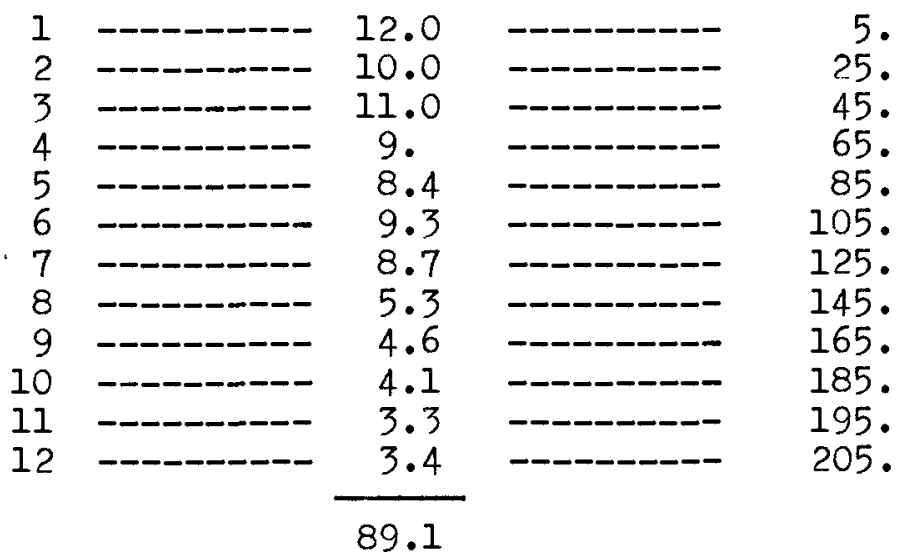

cifras que revelan que la menor densidad arenosa del viento no es también uniforme en altitud pues los pesos de los tubos 3, 6 y 12 son poco mayores que los de sus inmediatos inferiores. De todos modos, estos guarismos expresan que el transporte en altitud sobre el zócalo es muy pequeño dado el largo tiempo de duración del experimento. Como en el caso de los esperimentos con BZ, las anomalías de gradientes de deposición posiblemente se deben a la misma causa o sea mayor densidad de los granos de mineral o a desigual distribución de ellos en el viento, siendo esto lo más probable.

En otro experimento con $\mathrm{BH}, 50 \mathrm{~m}$. sur de la cresta intersección de la trocha de carros de Santa Rosa a Playa Grande con tubos $20 \mathrm{~cm}$. de diferencia de nivel, se obtuvo del 28 de febrero al 8 de marzo de 1958:

Tubos de abajo BH Meridional Altura sobre el suelo BH Setentriohacia arriba Peso de arena de la tangente infe- nal o sea con
No $\mathrm{mg}$ rior a la boca del tu mayor fetch bo

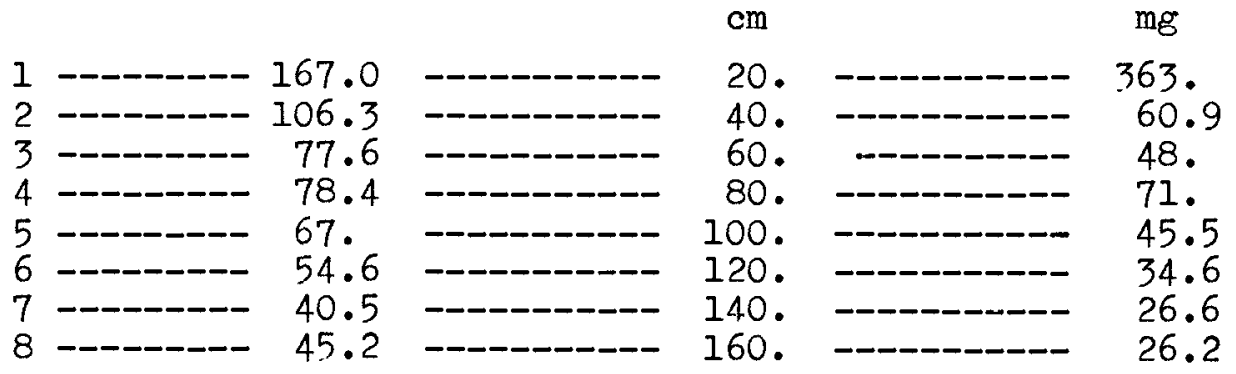

- Peso de arena 


\section{COASTAL ENGINEERING}

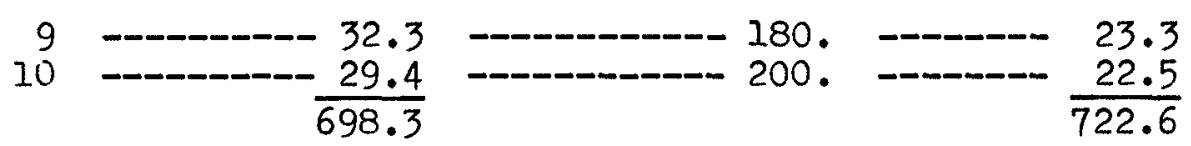

Las primeras experiencias con BH, habían sido hechas por mi padre el 11 de febrero de 1958 con tres BH (también llamados palos entubados) y con solo 3 tubos a 10,20 y $30 \mathrm{~cm}$. de alturas de boca sobre el suelo arenoso de la playa Santa Rosa en tres puntos distantes $25 \mathrm{~m}$. uno de otro y $10 \mathrm{~m}$. de $1 \mathrm{a} 1$ inea mojada por la rompiente, quien obtuvo de las $\mathrm{h}$. $172 \mathrm{v}$ a las h. 1820 los siguientes pesos:

\section{$\mathrm{BH}$ No 1}

Altura del tubo sobre el suelo al bajar la

escalinata a la playa
$\mathrm{BH} \mathrm{N}^{\circ} 2$

$25 \mathrm{~m}$ al $\mathrm{S}$ del $\mathrm{N}^{\circ} 125 \mathrm{~m}$ al $\mathrm{S}$ del $\mathrm{N}^{\circ} 2$
Peso arena

$10 \mathrm{~cm}$
20
$30 "$

\section{Peso arena}

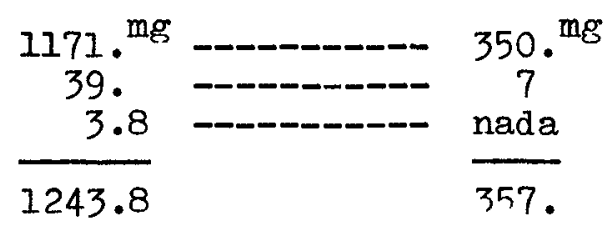

Estimación en peso del transporte eoloarenoso.- La irregularidad de las trayectorias de los granos de arena dentro del viento y la turbulencia de éste, son incógnitas que dificultan una estimación precisa del transporte arenoso con los arenómetros. Solo se pueden hacer estimaciones aproximadas a base de posibilidades, como serían las de considerar que en promedio las trayectorias de los granos de arena sean rectas horizontales y la turbulencia sea mínima o sea que el viento sea laminar y horizontal con densidad arenosa proporcionalmente decreciente en altitud. El área efectiva de captación de cada tubo BZ en este caso, seria la normal a las corrientes horizontales o sea la proyección vertical de los círculos inclinados de sus bocas de 1.3 de diámetro interior. El espesor de las paredes de los tubos es de $\pm 1 \mathrm{~mm}$.

En la Fig. 2 del Anexo 6 se exhiben proyecciones verticales que viene a ser elipses con área de $93.83 \mathrm{~mm}$ ? o sea de $1 \mathrm{~cm}$ ? en cifras redondas, considerando los granos que al rebotar en los bordes del tubo caen dentro de él.

Como entre una y otra elipse de las 12 de captación de un $\mathrm{BZ}$, cabe considerar otras 11 de igual área virtual (véase Fig. 2 Anexo 6 y fotos de Anexo 3). puede estimarse la arena 


\section{MEDICIONES DE ARENA EOLICA EXTRAIDA DE LA PLAYA DE SANTA ROSA POR DEFLACION}

acarreada hacia las virtuales, por interpolación entre los pesos de arena del tubo inmediato inferior y el superior; o sea, por ejemplo, que en el Experimento I del Anexo 5 con el primer arenómetro, en vez de las pesadas registradas en los tubos 1 a 12 , se puede constituir el cuadro siguiente que comprende la sucesión vertical contínua de 23 elipses de captación con área de $1 \mathrm{~cm}$ ? cada una: 12 reales y li virtuales:

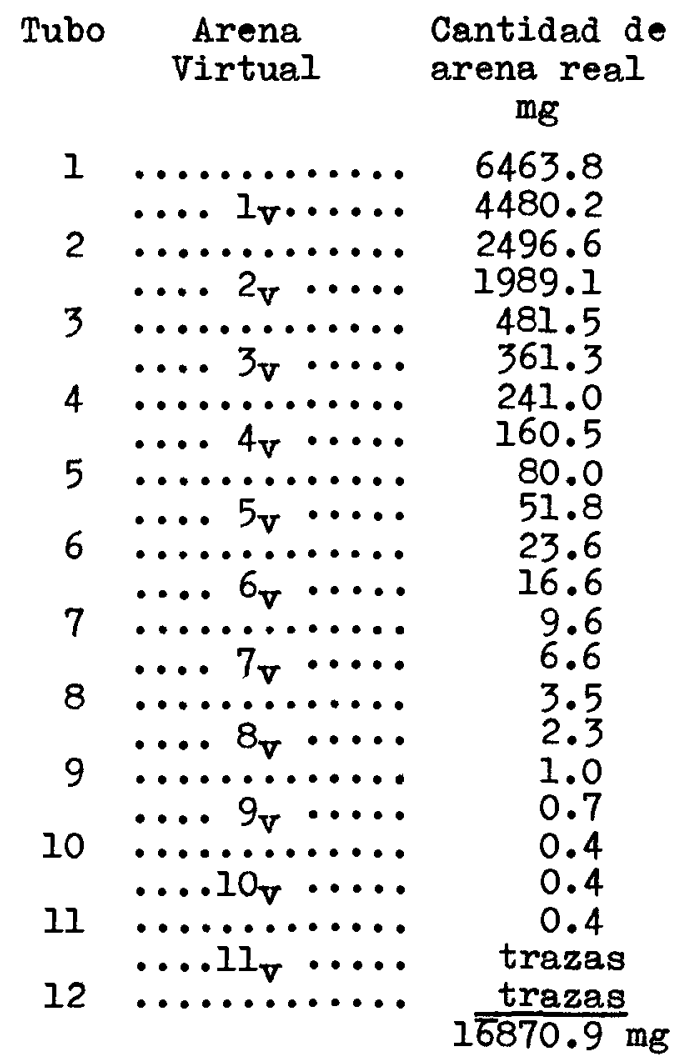

- sea que la columna contínua vertical de elipses reales $\mathrm{y}$ virtuales de bocas a $45^{\circ}$, habría captado $16870.9 \mathrm{mg}$ en vez de los $9801.4 \mathrm{mg}$ pesados realmente pesados.

En un estudio inédito de mi padre, sobre Agrupamientos Equicirculares, se demuestra que el poro máximo de un espacio intercircular de un tetracírculo equicircular o tetraequiclrculo, es igual en área a un solo equicírculo; y como se puede probar que igual cosa ocurre con las elipses, a cada columna BZ de 12 tubos de prueba le corresponde 12 medias elipses de captación a cada lado por concepto de espacio poral entre columna y columna tangente, con 10 que el área restangular circunscrita a las elipses sería el doble de la calculada por 


\section{COASTAL ENGINEERING}

los pesos reales y virtuales. Esto se podría expresar llamando $A_{r}$ al área elíptica de captación real y $A_{v}$ la virtual, por la fórmula:

$$
A_{c}=2\left(A_{r}+A_{v}\right)
$$

Para los efectos de una estimación más precisa, hemos calculado que el diámetro medio interior de cada tubo de prueba es de $13 \mathrm{~mm}$. y el exterior de $15 \mathrm{~mm}$. y como los granos que inciden sobre la pared redondeada de la boca de cada tubo rebotan en promedio con ángulo de reflexión igual al de la incidencia hacia el interior o exterior de cada tubo, se puede considerar solo $1 \mathrm{~mm}$. como espesor efectivo adıcional al área elíntica de captación o sea que tal columna rectangular de captación tendría $15 \mathrm{~mm}$. de ancho horizontal y que en cada metro horizontal habría:

$\frac{1000 \mathrm{~mm}}{15 \mathrm{~mm}}=66.66$ columnas de captación contínua de $9.19 \mathrm{~mm} \mathrm{x}$ $12 \times 12=220.56 \mathrm{~mm}$ de altura más $24 \mathrm{~mm}$ por espesor del vidrio desde el nivel de la tangente inferior a la boca del tubo más bajo hasta el de la superior al tubo más alto o sea lo que prácticamente es la altura del zócalo Eoloarenoso o sea $250 \mathrm{~mm}$.

Ia estimación a base del promedio de las tres mediciones del Anexo 5 Experimento $I$, nos daría así el peso de $37835.4 \mathrm{mg}$ por hora de viento normal en las condiciones especificadas en los cuadros respectivos, que duplicándolo arrojaría $75670 \mathrm{mg}$ ó sea la media de $25225 \mathrm{mg}$ por columna $\mathrm{y}$ por centímetro y medio de frente perpendicular al viento, que daría 252'250.000 mg de arena por cada $150 \mathrm{~m}$. de playa en una hora con una superficie seca anterior o fetch eoloarenoso seco de $10 \mathrm{~m}$. o sea $253 \mathrm{ks}$. o en cifras redondas $1 / 4$ de tonelada métrica. Esto equivale a $168148850 \mathrm{mg}$. por $100 \mathrm{~m}$. de playa o sea casi $170 \mathrm{ks}$. en una hora.

Con el fin de saber los límites de los cuales varía el transporte arenoso de acuerdo con las mediciones efectuadas por los arenómetros $B Z$ desde el nivel del suelo hasta $\pm 0.25 \mathrm{~m}$. que es lo que se considera el zócalo para lo cual nos valemos de unidades de extracción arenosa o sea extracción por unidad de tiempo, encontramos que el máximo registrado corresponde al Experimento VIII del Anexo 4 o sea Experiencia con un solo arenómetro. El mínimo se halló en el $\mathrm{V}$ del mismo Anexo 4. Enn el primero se observó, el 17 de Abril, $39180 \mathrm{mg}$. en 30 minutos con solo 6 tubos ( 1 al 6) o sea en medio zócalo y el 5 de marzo solo $1.7 \mathrm{mg}$ en 362 minutos. 


\section{MEDICIONES DE ARENA EOLICA EXTRAIDA DE LA PLAYA DE SANTA ROSA POR DEFLACION}

Formulando las columnas y los cálculos respectivos,obtenemos para estos dos casos extremos un transporte de 7 gramos por hora por cada $100 \mathrm{~m}$. de playa con velocidad de viento de $3 \mathrm{~m} / \mathrm{s}$ a la altura de $\mathrm{BZ}$ por un máximo de $1746 \mathrm{ks}$. con viento en ráfagas que exedieron de $20 \mathrm{~m} / \mathrm{s}$ y promedio de $8.5 \mathrm{~m} / \mathrm{s}$. Este viento fuerte del $\mathrm{SW}$ se inicio antes de las $10 \mathrm{a} . \mathrm{m}$. y durb hasta las $4 \mathrm{p.m}$. en que continuo fuerte pero con menos intensidad.

En esta misma tarde se coloco un $\mathrm{BH}$ sobre la duna de sombra del Morro de Santa Rosa en la parte más alta o cresta, desde h.1230 hasta h.1800 registrándose en tubos a desnivel de $10 \mathrm{~cm}$. entre si.

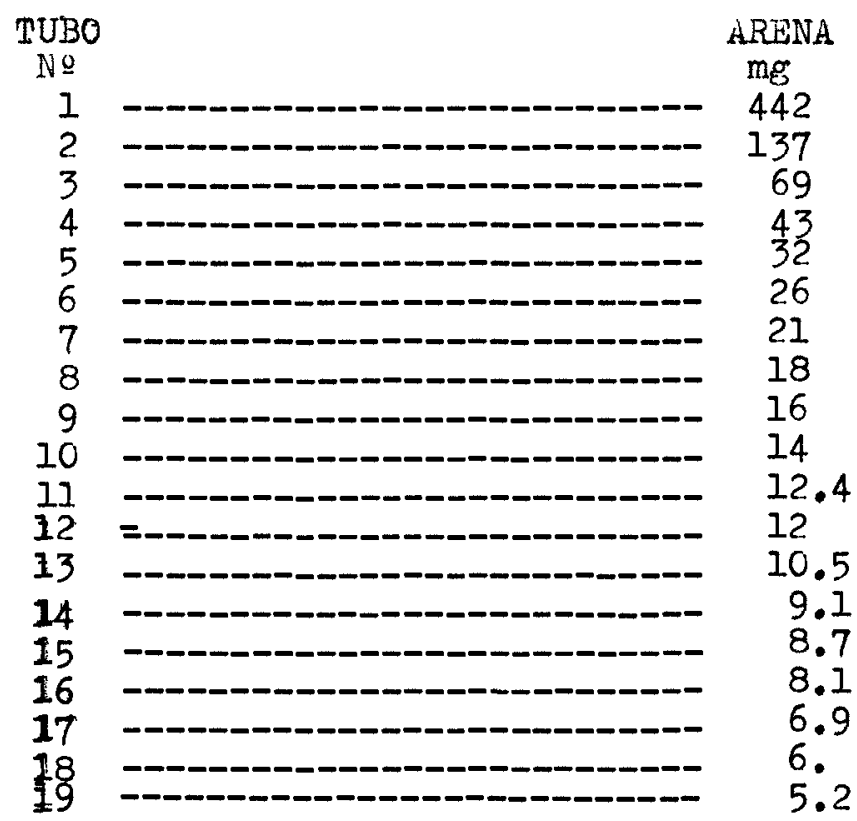

NOTA.- Il tubo ne l estubo a $5 \mathrm{~cm}$. sobre el suelo de la cresta de la duna de sombra del Morro Santa Rosa.

\section{CONCLUSIONES}

1.- Una playa arenosa en clima árido seco,con viento predominante de mar a tierra ( $S . S S W$ ) de velocidad no menor a los $5 \mathrm{~m} / \mathrm{s}$ caracterizado por ráfagas (golpes de viento), que incida sobre una franja de playa de arena de superficie suficientemente desecada, proporciona las condiciones principales que favorecen al transporte eoloarenoso. Determinando asi un proceso geomorfológico tipico de las áreas arenosas, en donde la deflación por el viento en 


\section{COASTAL ENGINEERING}

la playa arenosa y la deposición sobre ella de arena acarreada por el mar, pasa desaperoibido en un medio ambiente donde la litósfera, la hidrósfera y la atmósfera juegjan cada una de ellas un rol importante en la realización de este fenómeno eblico clásico.

2.- Las playas tendidas de más o menos 30 de inclinación, ofreciendo mayor área de exposición al viento y de deposición de arenas aportadas por corrientes de fondo (submarinas), son las de más fuerte y voluminosa extracción eblice, siempre y cuando se cumplan las condiciones expuestas en el acápite $\mathrm{N} \cong 1$ y se sumen: una favorahle amplitud de mareas $v$ oleajes, baja humedad atmosférica, e insolación;elavorando asi, los factores imprescindibles para la deflación playera

3.- El mayor porcentaje de arena acarreada por el viento por deflación tiene lugar a muy baja altura, siendo mayormente por arrastre, rotación y saltación, en el aerozbcalo( $25 \mathrm{~cm})$.

\section{BIBIIOGRAFIA}

AMSTUTZ.g.c. Raimundo Chico. Sand size fraction of South Peruvian barchans and a brief review of the genetic grain shape funtion. Separata of Bull. Ver Schweizer Petrol.Geol.u ing. Vol 24 kebruary 1958.

BROGGI.J.A.Migración de arenas a 10 largo de la Costa Peruana. Bol.Soc.Geol.del Perú.T. XXIV (Vol.Unıco).1952.

HJISTRON O HJULSTROEM. FIIIP.Bull. Geological Institution of University of upsala, Vol.XXV.

KRUMBEIN.W.X. and Pettijohn. Manual of Sedimentary Petrography.

KNOWLES MIDDIETON.W.E., and Spilhaus F.,Athelstan. Meteorological Instruments, 3rd. id revised University of Toronto Press p.136. 1953.

IAHEB F.H.Field Geology.p. 34, tid. 1941

MINIŚlERIO DE jidRIN 4 República Peruana.Tablas de mareas.Servicio Hidrológico 1958 y 1959

RUBEY, William $W$. The force required to move particles on a stream bed.U.S. Geological Survey,Professional Paper, 189-Ed. 1938.

WEBERBAUER, A. El Mundo Vegetal de los Andes Peruanos p.776, 1945. 
MEDICIONES DE ARENA EOLICA EXTRAIDA DE LA

PLAYA DE SANTA ROSA POR DEFLACION

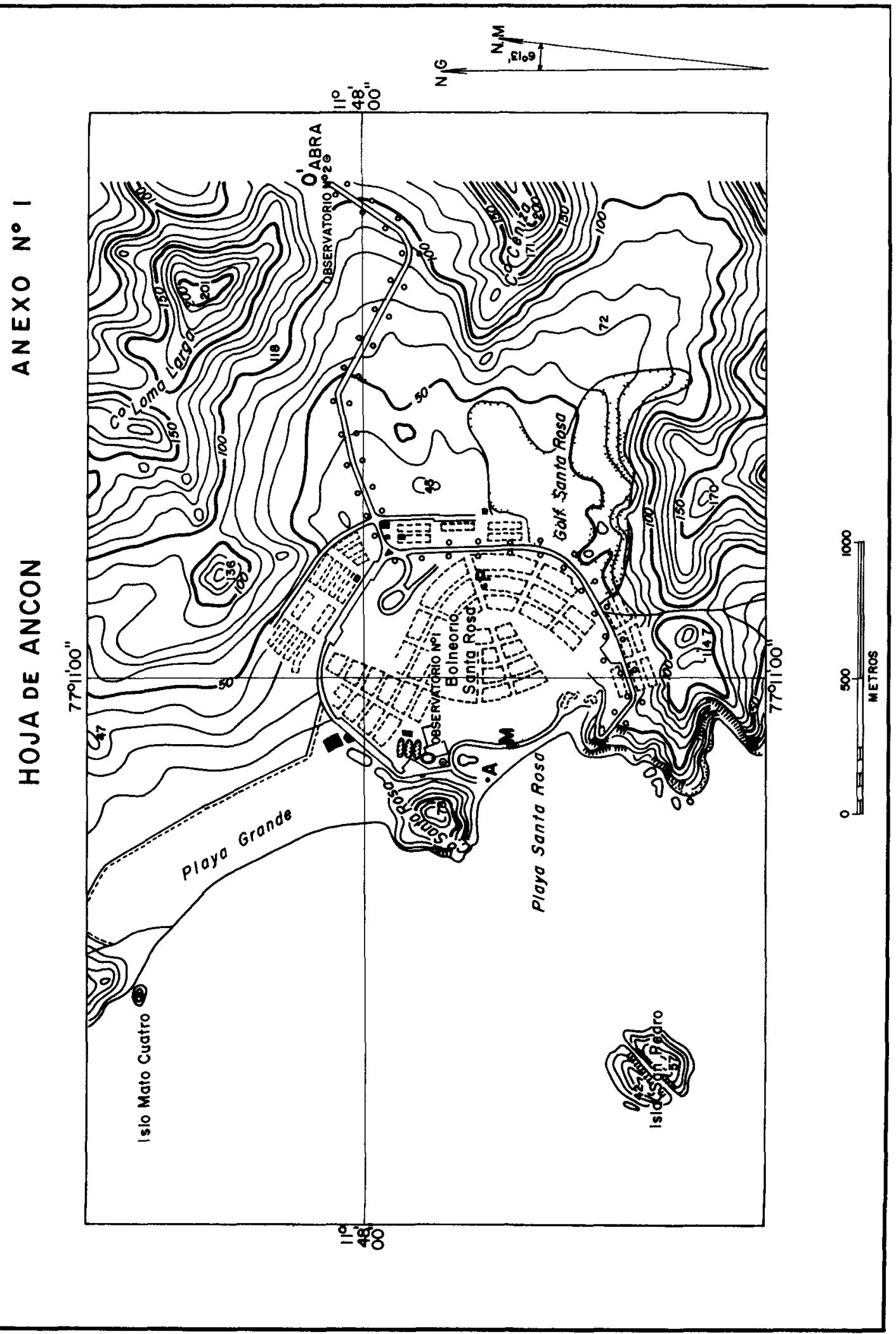


COASTAL ENGINEERING

\author{
ANEXO, NO. 2
}

OBSER VACIONES ME TEOROLOGICAS EN IA URBANIZACION

SANTA ROSA

(Observatorio No. 1)

\begin{tabular}{|c|c|c|c|c|c|c|c|c|c|}
\hline \multicolumn{7}{|c|}{ 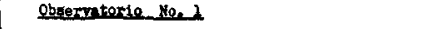 } & \multicolumn{3}{|c|}{ Julie_ 2957} \\
\hline \multirow[t]{2}{*}{$x_{n}$} & \multicolumn{3}{|c|}{$\begin{array}{c}\text { Ce } \\
\text { TEMPERATURA }\end{array}$} & \multicolumn{3}{|c|}{ 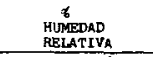 } & \multicolumn{3}{|c|}{$\begin{array}{l}\text { m/aeg } \\
\text { VELOCIDAD } \\
\text { DEL VERTEO }\end{array}$} \\
\hline & \multicolumn{3}{|c|}{$7{\underset{13}{\text { Horas }}}_{18}$} & \multicolumn{3}{|c|}{$7{ }_{13}^{\text {Hores }}{ }_{18}$} & \multicolumn{3}{|c|}{$7 \stackrel{\text { Horae }}{13}_{18}$} \\
\hline $\begin{array}{l}7 \\
8\end{array}$ & 20 & 21 & 22 & 70 & 60 & 65 & 0 & 6 & \\
\hline $\begin{array}{l}8 \\
9\end{array}$ & 19 & 21 & 22 & 59 & 60 & 63 & 2 & 4 & 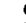 \\
\hline 10 & 19 & 20 & 22 & $\infty$ & $\infty$ & 60 & 2 & 6 & e \\
\hline u & 28 & 20 & $\begin{array}{l}21 \\
21\end{array}$ & $\stackrel{68}{m}$ & 63 & $\infty$ & 2 & 8 & se \\
\hline 12 & 28 & 20 & 21 & 73 & 70 & 73 & 2 & 4 & 8 \\
\hline 13 & 19 & 20 & 21 & 75 & 70 & 72 & 2 & 4 & 2 \\
\hline 14 & - & - & - & - & - & - & - & - & 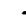 \\
\hline 25 & $=$ & - & * & - & - & - & - & - & 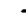 \\
\hline 26 & 18 & 20 & 21 & 71 & 70 & 72 & 0 & 2 & 4 \\
\hline 17 & 19 & 20 & 21 & 72 & 68 & 72 & 0 & 0 & 2 \\
\hline 18 & 19 & 20 & 21 & 96 & 75 & 73 & 0 & 2 & s \\
\hline 19 & 16 & 29 & 20 & 85 & B3 & 85 & 2 & 4 & 6 \\
\hline 20 & 19 & 19 & 20 & 90 & 65 & 85 & 0 & 4 & 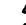 \\
\hline 21 & 21 & 20 & 21 & 85 & 80 & 89 & 2 & 4 & 6 \\
\hline 22 & 20 & 20 & 21 & 73 & 65 & 70 & 2 & 4 & 6 \\
\hline 23 & $=$ & - & - & - & - & - & - & - & 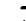 \\
\hline 24 & 19 & 20 & 21 & 72 & 65 & 70 & 2 & 4 & 4 \\
\hline 25 & 19 & 21 & 20 & 73 & 68 & 72 & 2 & 2 & 2 \\
\hline 26 & 19 & 19 & 20 & 75 & 65 & 70 & 2 & 6 & 10 \\
\hline 27 & 19 & 16 & 20 & 72 & 65 & 70 & 2 & 8 & 20 \\
\hline 28 & 19 & 18 & 21 & 75 & 68 & 70 & 2 & 6 & 10 \\
\hline 29 & 19 & 18 & 20 & 75 & 68 & 71 & 2 & o & 14 \\
\hline 30 & 19 & 18 & 21 & 73 & 65 & 70 & 2 & 2 & 4 \\
\hline 31 & 19 & 18 & 20 & 73 & $n$ & 71 & 4 & 6 & 14 \\
\hline Heas $x^{2}$ & 13 & 14 & 15 & 52 & 49 & 50 & 2 & 4 & 7 \\
\hline 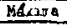 & 21 & 21 & 22 & 90 & 85 & 85 & 4 & $\theta$ & 14 \\
\hline Minzilas & 18 & 18 & 20 & 59 & 60 & 60 & 0 & 0 & 2 \\
\hline
\end{tabular}

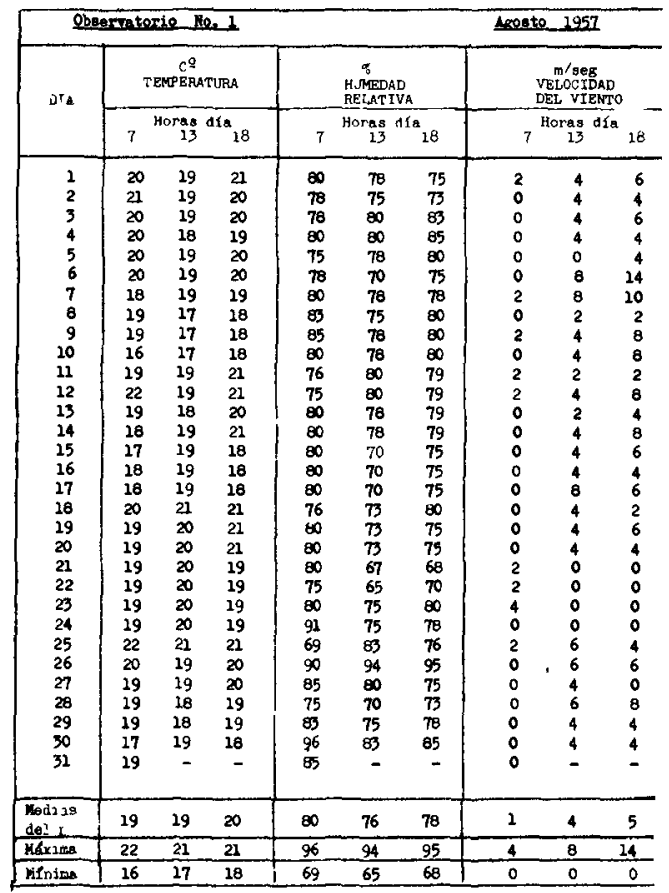

\begin{tabular}{|c|c|c|c|c|c|c|c|c|c|}
\hline \multicolumn{4}{|c|}{ Obactintarte toul } & & & \multicolumn{4}{|c|}{ Setifiabre 1957} \\
\hline \multirow[t]{2}{*}{$J^{x}$} & \multicolumn{3}{|c|}{ TEMPERATUAA } & \multicolumn{3}{|c|}{$\underset{\substack{* \\
\text { MUMEDAD } \\
\text { BELATIVA }}}{x}$} & \multicolumn{3}{|c|}{$\begin{array}{l}\text { m/aEg } \\
\text { VELOCIDAD } \\
\text { DEL VIENTO }\end{array}$} \\
\hline & & ras & ${ }_{18}$ & & $\begin{array}{r}\text { rass } \\
13\end{array}$ & 18 & & ras & \\
\hline $\begin{array}{l}1 \\
2 \\
3 \\
4 \\
5 \\
8 \\
1 \\
8 \\
9 \\
10 \\
11 \\
12 \\
13 \\
14 \\
15 \\
16 \\
17 \\
28 \\
19 \\
20 \\
21 \\
22 \\
23 \\
24 \\
29 \\
26 \\
27 \\
28 \\
29 \\
30\end{array}$ & $\begin{array}{l}19 \\
0 \\
16 \\
16 \\
16 \\
17 \\
16 \\
17 \\
16 \\
18 \\
18 \\
19 \\
18 \\
19 \\
19 \\
17 \\
19 \\
19 \\
17 \\
16 \\
17 \\
17 \\
18 \\
19 \\
16 \\
17 \\
17 \\
17 \\
16 \\
17\end{array}$ & $\begin{array}{l}20 \\
19 \\
19 \\
19 \\
18 \\
18 \\
17 \\
18 \\
19 \\
19 \\
19 \\
19 \\
19 \\
18 \\
17 \\
19 \\
18 \\
18 \\
19 \\
16 \\
19 \\
19 \\
19 \\
16 \\
18 \\
18 \\
18 \\
16 \\
19 \\
19\end{array}$ & $\begin{array}{l}19 \\
19 \\
19 \\
18 \\
19 \\
19 \\
19 \\
17 \\
18 \\
18 \\
18 \\
18 \\
19 \\
19 \\
19 \\
19 \\
19 \\
20 \\
19 \\
19 \\
18 \\
18 \\
18 \\
19 \\
19 \\
19 \\
19 \\
19 \\
19 \\
19\end{array}$ & $\begin{array}{l}60 \\
90 \\
80 \\
80 \\
80 \\
80 \\
85 \\
85 \\
85 \\
85 \\
85 \\
85 \\
85 \\
85 \\
85 \\
85 \\
73 \\
75 \\
75 \\
80 \\
80 \\
85 \\
85 \\
80 \\
85 \\
85 \\
80 \\
69 \\
85 \\
83\end{array}$ & $\begin{array}{l}76 \\
80 \\
73 \\
73 \\
73 \\
80 \\
80 \\
73 \\
75 \\
73 \\
75 \\
80 \\
75 \\
73 \\
80 \\
75 \\
70 \\
70 \\
70 \\
73 \\
75 \\
75 \\
78 \\
78 \\
70 \\
73 \\
73 \\
75 \\
78 \\
72\end{array}$ & $\begin{array}{l}78 \\
83 \\
80 \\
75 \\
75 \\
83 \\
85 \\
72 \\
78 \\
76 \\
70 \\
65 \\
80 \\
80 \\
83 \\
83 \\
75 \\
75 \\
78 \\
80 \\
80 \\
70 \\
80 \\
80 \\
80 \\
70 \\
70 \\
70 \\
80 \\
80\end{array}$ & $\begin{array}{l}4 \\
2 \\
2 \\
2 \\
4 \\
4 \\
4 \\
0 \\
0 \\
0 \\
2 \\
2 \\
2 \\
2 \\
2 \\
2 \\
0 \\
0 \\
2 \\
2 \\
0 \\
2 \\
0 \\
2 \\
2 \\
2 \\
0 \\
0 \\
0 \\
4\end{array}$ & $\begin{array}{l}6 \\
4 \\
4 \\
4 \\
6 \\
6 \\
4 \\
0 \\
2 \\
2 \\
6 \\
4 \\
4 \\
4 \\
4 \\
4 \\
4 \\
4 \\
4 \\
4 \\
2 \\
2 \\
0 \\
2 \\
4 \\
4 \\
4 \\
6 \\
6 \\
6\end{array}$ & $\begin{array}{l}8 \\
4 \\
4 \\
6 \\
4 \\
6 \\
6 \\
4 \\
4 \\
4 \\
4 \\
6 \\
4 \\
4 \\
4 \\
4 \\
6 \\
4 \\
4 \\
4 \\
2 \\
0 \\
0 \\
4 \\
4 \\
6 \\
8 \\
8 \\
8\end{array}$ \\
\hline $\begin{array}{ll}\text { Mor } & 19 \\
d e+2\end{array}$ & 18 & 19 & 19 & 83 & 73 & 79 & 2 & 4 & 5 \\
\hline Boxar & 20 & 20 & 20 & 90 & 60 & 85 & 4 & 6 & 6 \\
\hline WInI & 16 & 27 & 17 & 75 & 70 & 72 & 0 & 0 & 0 \\
\hline
\end{tabular}

\begin{tabular}{|c|c|c|c|c|c|c|c|c|c|}
\hline \multicolumn{7}{|c|}{ 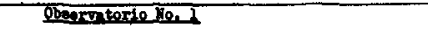 } & \multicolumn{3}{|c|}{ octube 2957} \\
\hline \multirow[t]{2}{*}{$a^{2} x_{2}$} & \multicolumn{3}{|c|}{$\begin{array}{c}C^{\mathbf{q}} \\
\text { TENEERATURA }\end{array}$} & \multicolumn{3}{|c|}{$\begin{array}{l}\text { HNMEDAD } \\
\text { RELATIVA }\end{array}$} & \multicolumn{3}{|c|}{$\begin{array}{l}\mathrm{m} / \mathrm{seg} \\
\text { VSLOCIDAD } \\
\text { DFL VIENTO }\end{array}$} \\
\hline & \multicolumn{3}{|c|}{${ }_{7}^{\text {Hortas dis }}{ }_{18}$} & \multicolumn{3}{|c|}{$7{ }_{13}^{\text {Horas }}{ }_{18}$} & \multicolumn{3}{|c|}{$7_{13}^{\text {Horas dia }} 28$} \\
\hline 1 & 16 & & 27 & 83 & 72 & 78 & 0 & 2 & 4 \\
\hline 2 & 16 & 18 & 27 & 80 & 70 & 73 & 0 & 6 & 8 \\
\hline 3 & 16 & 19 & 17 & 80 & 75 & 78 & 4 & 4 & 2 \\
\hline 4 & 17 & 18 & 17 & 83 & 70 & 73 & 2 & 4 & 6 \\
\hline 5 & 17 & 18 & 17 & 85 & 70 & 73 & 0 & 4 & 4 \\
\hline 6 & 18 & 19 & 17 & 75 & 70 & 78 & 0 & 4 & 6 \\
\hline 7 & 17 & 18 & 17 & 83 & al & 83 & 2 & 4 & 6 \\
\hline 8 & 16 & 18 & 17 & 83 & 80 & gl & 0 & 4 & 6 \\
\hline 9 & 18 & 18 & 27 & 81 & 80 & 81 & 0 & 4 & 6 \\
\hline 10 & 18 & 19 & 17 & 80 & 73 & 80 & 0 & 4 & 4 \\
\hline 11 & 18 & 17 & 18 & 83 & 75 & 80 & 0 & 4 & 6 \\
\hline 12 & 18 & 27 & 19 & 85 & 75 & 70 & 0 & 4 & 4 \\
\hline 23 & 19 & 18 & 18 & 75 & 70 & 74 & 0 & 2 & 4 \\
\hline 14 & 19 & 18 & 19 & 78 & 70 & 75 & 0 & 2 & 4 \\
\hline 15 & 19 & 21 & 20 & 78 & 75 & 76 & 0 & 2 & 6 \\
\hline 16 & 20 & 19 & 29 & $\infty$ & 75 & 80 & 0 & 2 & 4 \\
\hline 17 & 21 & 19 & 19 & 85 & 8 & 93 & 0 & 4 & 2 \\
\hline 10 & 20 & 16 & 19 & 83 & 75 & 80 & 0 & 8 & 10 \\
\hline 19 & 20 & 19 & 19 & 85 & $\frac{1}{15}$ & $\infty$ & 0 & 4 & 6 \\
\hline 20 & 20 & 19 & 20 & 75 & 70 & 70 & 2 & 0 & 2 \\
\hline 21 & 21 & 19 & 20 & 78 & 70 & 75 & 0 & 2 & 2 \\
\hline 22 & 21 & 19 & 20 & 75 & 70 & 73 & 2 & 4 & $\overline{6}$ \\
\hline 23 & 20 & 19 & 21 & 75 & 70 & 75 & 2 & 4 & 6 \\
\hline 24 & 2 & 19 & 20 & 80 & 75 & 78 & 2 & 4 & 6 \\
\hline 25 & 20 & 19 & 21 & 75 & 70 & 72 & 2 & 4 & 8 \\
\hline 26 & 21 & 19 & 20 & 78 & 70 & $\pi$ & 0 & 2 & 4 \\
\hline 27 & $\mathbf{2 1}$ & 19 & 20 & 70 & 65 & 70 & 4 & 6 & 4 \\
\hline 28 & 20 & 19 & 21 & 78 & 65 & 75 & 2 & 6 & 8 \\
\hline 29 & 21 & 18 & 20 & 78 & 65 & 80 & 0 & 4 & 6 \\
\hline 30 & 20 & 19 & 21 & 80 & 65 & 75 & 4 & 4 & 6 \\
\hline 31 & 20 & 19 & 21 & 80 & 65 & 75 & 4 & 0 & 4 \\
\hline Medias & 19 & 19 & 19 & 80 & 72 & $\pi$ & 2 & 4 & 5 \\
\hline Maxme & 21 & 21 & 21 & 85 & 81 & 보 & 4 & 6 & 30 \\
\hline Minima & 16 & 27 & 27 & 75 & 63 & 70 & 0 & 0 & 2 \\
\hline
\end{tabular}


MEDICIONES DE ARENA EOLICA EXTRAIDA DE LA PLAYA DE SANTA ROSA POR DEFLACION

ANEXO NO. 2

\begin{tabular}{|c|c|c|c|c|c|c|c|c|c|}
\hline \multicolumn{7}{|c|}{ Obeervatorio Noe 1} & \multicolumn{3}{|c|}{ Novdenbre 2957} \\
\hline \multirow[t]{2}{*}{$x^{2}$} & \multicolumn{3}{|c|}{$\begin{array}{c}\mathrm{C}^{2} \\
\text { TEMPRATURA }\end{array}$} & \multicolumn{3}{|c|}{$\begin{array}{c}\mathscr{8} \\
\text { MUMRDAD } \\
\text { RELATIYA }\end{array}$} & \multicolumn{3}{|c|}{$\begin{array}{l}\text { m/seg } \\
\text { VELOCIDAD } \\
\text { DEL VIENTO }\end{array}$} \\
\hline & \multicolumn{3}{|c|}{7 Horas d ${ }_{13}{ }_{18}$} & \multicolumn{3}{|c|}{$7_{13}^{\text {Horas dia }} 16$} & \multicolumn{3}{|c|}{$7 \stackrel{\text { Horas dia }}{13}{ }_{18}$} \\
\hline 1 & 21 & & 19 & 85 & 68 & & & 2 & \\
\hline 2 & 20 & 19 & 21 & 83 & 63 & 78 & & 2 & 4 \\
\hline 3 & 21 & 18 & 20 & 85 & 65 & 75 & . & 4 & 6 \\
\hline 4 & 21 & 19 & 20 & 83 & 73 & 75 & . & 5 & 4 \\
\hline 5 & 21 & 19 & 21 & 85 & 75 & $\infty$ & . & - & 4 \\
\hline 6 & 20 & 18 & 20 & 83 & 78 & 80 & - & 4 & 6 \\
\hline 7 & 21 & 19 & 20 & 80 & 75 & 80 & & 4 & 6 \\
\hline 8 & 21 & 14 & 19 & 85 & 70 & 83 & . & 6 & 8 \\
\hline 9 & 21 & 16 & 19 & 83 & 75 & 83 & & 4 & 6 \\
\hline 10 & 21 & 19 & 20 & 80 & 75 & 78 & . & - & 4 \\
\hline 11 & 21 & 19 & 21 & 85 & 78 & 80 & . & 4 & 6 \\
\hline 12 & 20 & 19 & 21 & 80 & 75 & $\infty$ & & 6 & 8 \\
\hline 13 & 20 & 19 & 21 & 80 & 75 & 83 & & 4 & 6 \\
\hline 14 & 19 & 17 & 21 & 83 & 63 & 70 & 2 & 6 & 8 \\
\hline 15 & 19 & 18 & 19 & 83 & 73 & 80 & & 4 & 6 \\
\hline 16 & 20 & 19 & 21 & 80 & 75 & 70 & & 4 & 6 \\
\hline 17 & 22 & 20 & 21 & 65 & 63 & 65 & 8 & 10 & 10 \\
\hline 18 & 21 & 29 & 20 & 70 & 65 & 70 & & 8 & 10 \\
\hline 19 & 20 & 19 & 21 & 75 & 63 & 70 & 6 & 10 & 4 \\
\hline 20 & 19 & 14 & 19 & 83 & 70 & 83 & & 6 & 10 \\
\hline 21 & 19 & 14 & 19 & 83 & 73 & 65 & 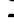 & 6 & 8 \\
\hline 22 & 18 & 14 & 19 & 82 & 65 & 80 & & 4 & B \\
\hline 23 & 19 & 15 & 19 & 80 & 63 & 80 & 0 & 6 & 6 \\
\hline 24 & 19 & 25 & 20 & 82 & 65 & 80 & 2 & 4 & 4 \\
\hline 25 & 29 & 14 & 19 & 82 & 65 & 80 & 4 & 6 & 4 \\
\hline 26 & 19 & 15 & 19 & 83 & 64 & 85 & 4 & B & 10 \\
\hline 27 & 19 & 14 & 18 & 85 & 65 & 84 & 4 & 6 & 8 \\
\hline 28 & 19 & 25 & 19 & 83 & 65 & 80 & $a$ & 6 & 8 \\
\hline 29 & 19 & 14 & 29 & 83 & 67 & 63 & 4 & 6 & 20 \\
\hline 30 & 19 & 15 & 18 & 83 & 63 & 85 & 2 & 4 & 6 \\
\hline 31 & - & - & - & - & - & - & - & - & - \\
\hline $\begin{array}{l}\text { Weat } \\
\text { del }\end{array}$ & 20 & 17 & 20 & 81 & 69 & 78 & 3 & 5 & 7 \\
\hline MG $6 \times 3 n$ & 22 & 20 & 21 & 85 & 78 & 85 & 8 & 10 & 20 \\
\hline$M f_{\text {nli }}$ & 18 & 14 & 18 & 65 & 63 & 65 & 0 & 2 & 4 \\
\hline
\end{tabular}

\begin{tabular}{|c|c|c|c|c|c|c|c|c|c|}
\hline \multicolumn{7}{|c|}{ Observatoride $\mathrm{Nen}$} & \multicolumn{3}{|c|}{ Dreiombere 197} \\
\hline \multirow{2}{*}{$L^{r_{A}}$} & \multicolumn{3}{|c|}{$\begin{array}{l}C^{\underline{O}} \\
\text { TEMPEBATURA }\end{array}$} & \multicolumn{3}{|c|}{ 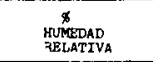 } & \multicolumn{3}{|c|}{ 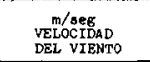 } \\
\hline & \multicolumn{3}{|c|}{${ }_{7}^{\text {Horas }}{ }_{13}{ }^{1 / a_{28}}$} & \multicolumn{3}{|c|}{${ }_{13}^{\text {Horas a1g }}{ }_{18}$} & \multicolumn{3}{|c|}{$7{ }_{13}^{\text {Horag }}{ }_{12 .}{ }_{18}$} \\
\hline & & & & & & & 2 & 4 & \\
\hline 2 & 20 & 15 & 19 & 75 & 67 & 78 & 2 & 4 & \\
\hline 3 & 23 & 14 & 19 & 76 & 70 & 75 & $: 0$ & 0 & $\frac{2}{4}$ \\
\hline $\begin{array}{l}4 \\
5\end{array}$ & ${ }_{24}^{23}$ & & ${ }_{21}^{20}$ & $\begin{array}{l}60 \\
60\end{array}-1-10$ & 56 & $\begin{array}{l}60 \\
65\end{array}$ & 0 & $\begin{array}{l}2 \\
4\end{array}$ & 4 \\
\hline 6 & 21 & & 20 & 65 & 56 & 60 & 0 & 4 & 2 \\
\hline 7 & 22 & 19 & 20 & 65 & 62 & 65 & 0 & 4 & 8 \\
\hline 8 & 22 & 22 & 21 & 65 & 62 & 63 & 4 & 6 & 8 \\
\hline${ }_{10}^{9}$ & 22 & 16 & 22 & $\begin{array}{l}65 \\
70\end{array}$ & 62 & 64 & $0_{0}^{4}-3-3-5$ & 8 & 8 \\
\hline 10 & & & 19 & 67 & ${ }_{64}^{02}$ & $\begin{array}{l}65 \\
67 \\
67\end{array}$ & 0 & 4 & 6 \\
\hline 12 & 22 & 15 & 21 & 68 & 63 & 65 & 2 & $\begin{array}{l}4 \\
4\end{array}$ & 8 \\
\hline 13 & 22 & 15 & 18 & 75 & 65 & 65 & 0 & 2 & 6 \\
\hline 14 & 22 & 15 & 19 & 75 & 65 & 70 & 2 & 4 & 6 \\
\hline 15 & 20 & 15 & 19 & 80 & 65 & 75 & 4 & 6 & 8 \\
\hline 16 & 21 & 16 & 19 & 8 & 67 & 75 & 0 & $\circ$ & 2 \\
\hline $\begin{array}{l}17 \\
18\end{array}$ & & & 19 & 80 & & 75 & 1 & 6 & $\begin{array}{l}2 \\
8\end{array}$ \\
\hline 19 & & 15 & 19 & $\infty$ & 70 & $\begin{array}{l}10 \\
80\end{array}$ & 5 & 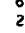 & 6 \\
\hline 20 & 20 & 18 & 19 & 80 & 70 & $\infty$ & 2 & 2 & 6 \\
\hline 21 & 20 & 17 & 19 & 83 & 73 & 80 & 2 & 4 & 6 \\
\hline 22 & 20 & 19 & 20 & 80 & 62 & $\begin{array}{l}70 \\
770\end{array}$ & 4 & 6 & 0 \\
\hline $\begin{array}{l}23 \\
24\end{array}$ & $\begin{array}{l}20 \\
22\end{array}$ & $\begin{array}{l}19 \\
17\end{array}$ & $\begin{array}{l}20 \\
19\end{array}$ & $\begin{array}{l}83 \\
83\end{array}$ & $\begin{array}{l}73 \\
73\end{array}$ & $\begin{array}{l}70 \\
76\end{array}$ & 4 & $\begin{array}{l}6 \\
6\end{array}$ & $\begin{array}{l}8 \\
6\end{array}$ \\
\hline 25 & 25 & 22 & 23 & 81 & 73 & 78 & 4 & 6 & 8 \\
\hline 26 & 28 & $\begin{array}{l}25 \\
\end{array}$ & 28 & 83 & 73 & $\infty$ & 1 & 6 & 8 \\
\hline $\begin{array}{r}27 \\
28 \\
28\end{array}$ & $\begin{array}{l}28 \\
27\end{array}$ & ${ }_{25}^{25}$ & $\begin{array}{r}28 \\
27\end{array}$ & ${ }_{80}^{81}$ & $\begin{array}{l}73 \\
70\end{array}$ & $\begin{array}{l}80 \\
\infty\end{array}$ & $0_{0}^{4}$ & $\begin{array}{l}6 \\
4\end{array}$ & $\begin{array}{l}8 \\
6\end{array}$ \\
\hline $\begin{array}{l}28 \\
29 \\
29\end{array}$ & $\begin{array}{l}27 \\
27\end{array}$ & ${ }_{21}^{21}$ & $\begin{array}{l}27 \\
27\end{array}$ & $\begin{array}{l}80 \\
83\end{array}$ & $\begin{array}{l}70 \\
73\end{array}$ & $\begin{array}{l}\infty_{\infty}^{\infty} \\
\end{array}$ & a & $\begin{array}{l}4 \\
4\end{array}$ & 4 \\
\hline & 28 & 21 & 27 & on & 7 & 80 & 4 & 6 & 8 \\
\hline 31 & 27 & 19 & 21 & 80 & 70 & 80 & 0 & 0 & 4 \\
\hline $\mathrm{He}_{\mathrm{e} u \perp \mathrm{s}}$ & 23 & 18 & 21 & 75 & 67 & 73 & 2 & 4 & 6 \\
\hline KA & 28 & 25 & $\cdots$ & & 75 & 80 & 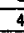 & 5 & 8 \\
\hline MInIn: & 20 & 14 & 14 & 60 & 56 & 60 & 0 & 0 & 0 \\
\hline
\end{tabular}


COASTAL ENGINEERING

A.REXO, INO. 2

OBSER VAGI ONES WE IEOROLUGICAS EN LA URBAINIZACION

SANTA ROSA

(Observatorio io. 2)

\begin{tabular}{|c|c|c|c|c|c|c|c|c|c|c|}
\hline \multicolumn{7}{|c|}{ Obaersatorio Non? } & \multicolumn{4}{|c|}{ Fnere 1958} \\
\hline \multirow{2}{*}{ DIA } & \multicolumn{3}{|c|}{ 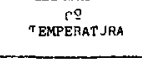 } & \multicolumn{3}{|c|}{$\begin{array}{c}6 \\
\text { HJRIEDAD } \\
\text { PELATIVA }\end{array}$} & \multicolumn{3}{|c|}{$\begin{array}{c}\mathrm{m} / \mathrm{seg} \\
\text { VELOCIDAD } \\
\text { DEL VIENTO }\end{array}$} & \multirow{2}{*}{$\begin{array}{c}\text { HORAS } \\
\text { DE } \\
\text { SOL }\end{array}$} \\
\hline & & Hora & ${ }_{18}$ & & $\begin{array}{r}\text { Horas } \\
1\end{array}$ & dín & & For & & \\
\hline 2 & 30 & 28 & 30 & 80 & 65 & 55 & 4 & 4 & 4 & - \\
\hline 2 & 30 & 27 & 30 & 80 & 65 & 75 & 0 & 4 & 4 & - \\
\hline 3 & 30 & 25 & 30 & 80 & 70 & 80 & 2 & 4 & 6 & 8 \\
\hline 4 & 30 & 26 & 23 & 80 & 70 & 80 & - & - & - & 7 \\
\hline 5 & 28 & 22 & 26 & $\infty$ & 60 & 80 & 4 & 6 & 8 & 11 \\
\hline 6 & 28 & 22 & 26 & 30 & 60 & 80 & 4 & 6 & 8 & 10 \\
\hline 7 & 29 & 26 & 288 & 60 & 60 & 75 & 2 & 4 & 6 & 10 \\
\hline 8 & 28 & 22 & 28 & 80 & 60 & 75 & 4 & 6 & 8 & 11 \\
\hline 9 & 30 & 22 & 28 & 80 & 60 & 75 & - & 4 & 6 & 11 \\
\hline 10 & 30 & 22 & 28 & 80 & 55 & 75 & 4 & 6 & 8 & 11 \\
\hline 11 & 27 & 25 & $\angle 8$ & 65 & 55 & 70 & 2 & 6 & 8 & 12 \\
\hline 12 & 30 & 30 & 28 & 75 & 55 & 60 & 0 & 0 & 2 & 10 \\
\hline 13 & 28 & 30 & 28 & 75 & 68 & 70 & 0 & 4 & $\theta$ & 11 \\
\hline 14 & 28 & 30 & 28 & 85 & 65 & 70 & 0 & 4 & 8 & 12 \\
\hline 15 & 28 & 30 & 28 & 85 & 65 & 70 & 2 & 4 & B & 10 \\
\hline 16 & 27 & 28 & 28 & 80 & 65 & 70 & 0 & 4 & 8 & 5 \\
\hline 17 & 26 & 28 & 29 & 80 & 65 & 75 & 0 & 4 & 6 & 10 \\
\hline 18 & 24 & 28 & 28 & 80 & 65 & 75 & 0 & 4 & 8 & 8 \\
\hline 19 & 26 & 28 & 26 & 90 & 65 & 70 & 2 & 6 & 8 & 12 \\
\hline 20 & 26 & 28 & 26 & 90 & 65 & 70 & 2 & 6 & B & 10 \\
\hline 21 & 26 & 30 & 26 & 85 & 60 & 70 & 2 & 4 & 6 & 10 \\
\hline 22 & 26 & 28 & 27 & 85 & 60 & 65 & 2 & 4 & a & 10 \\
\hline 23 & 26 & 27 & 27 & 85 & 65 & 70 & 0 & 4 & 6 & 10 \\
\hline 24 & 25 & 28 & 27 & 85 & 70 & 75 & 2 & 4 & 6 & 12 \\
\hline 25 & 25 & 28 & 27 & 85 & 70 & 75 & 0 & 4 & 8 & 12 \\
\hline 26 & 26 & 29 & 27 & 85 & 60 & 75 & - & - & - & 12 \\
\hline 27 & 26 & 28 & 26 & 80 & 65 & 75 & 4 & 6 & 8 & 10 \\
\hline 28 & 25 & 28 & 26 & 85 & 60 & 75 & 2 & 2 & 4 & 12 \\
\hline 29 & 26 & 28 & 27 & 80 & 60 & 70 & 4 & 4 & 6 & 12 \\
\hline 30 & 26 & 29 & 27 & 80 & 65 & 75 & 4 & 6 & 8 & 10 \\
\hline 31 & 25 & 28 & 26 & 85 & 60 & 70 & 4 & 6 & 6 & 12 \\
\hline Medlas & 28 & 27 & 28 & 82 & 63 & 73 & 2 & 5 & 7 & 10 \\
\hline Máxina & 30 & 30 & 30 & 90 & 70 & 80 & 4 & 6 & 8 & 12 \\
\hline Mnima & 24 & 22 & 26 & 65 & 55 & 55 & 0 & 0 & 2 & 5 \\
\hline
\end{tabular}

\begin{tabular}{|c|c|c|c|c|c|c|c|}
\hline \multicolumn{6}{|c|}{ Qbsertatorio Ho. 2} & \multicolumn{2}{|c|}{ Eebrexp 1958} \\
\hline \multirow{2}{*}{ DL } & \multicolumn{2}{|c|}{ 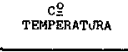 } & \multicolumn{3}{|c|}{ 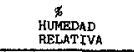 } & 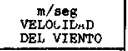 & \multirow{2}{*}{$\begin{array}{l}\text { Hopas } \\
\text { De } \\
\text { soL }\end{array}$} \\
\hline & , $\begin{array}{c}\text { Horas } \\
13\end{array}$ & ${ }_{18}^{d 8}$ & 7 & $\begin{array}{c}\text { Horanas } \\
13\end{array}$ & ${ }_{18}^{\mathrm{din}_{\mathrm{n}}}$ & $7{ }_{13}^{\text {Horas d1a }} 18$ & \\
\hline $\begin{array}{l}1 \\
2 \\
3 \\
4 \\
5 \\
5 \\
6 \\
7 \\
8 \\
8 \\
10 \\
11 \\
12 \\
12 \\
13 \\
14 \\
15 \\
16 \\
17 \\
18 \\
19 \\
20 \\
21 \\
22 \\
23 \\
24 \\
25 \\
26 \\
27 \\
28\end{array}$ & \begin{tabular}{|ll}
29 & 30 \\
27 & 29 \\
27 & 28 \\
28 & 29 \\
28 & 28 \\
28 & 29 \\
28 & 29 \\
29 & 25 \\
29 & 26 \\
30 & 25 \\
29 & 26 \\
29 & 26 \\
29 & 26 \\
29 & 26 \\
30 & 26 \\
29 & 27 \\
29 & 26 \\
29 & 26 \\
30 & 26 \\
29 & 25 \\
29 & 26 \\
29 & 26 \\
28 & 25 \\
29 & 25 \\
29 & 27 \\
29 & 27 \\
28 & 26 \\
29 & 27
\end{tabular} & $\begin{array}{l}27 \\
27 \\
27 \\
27 \\
29 \\
27 \\
27\end{array}$ & $\begin{array}{l}80 \\
85 \\
80 \\
85 \\
80 \\
80 \\
80 \\
80 \\
80 \\
80 \\
80 \\
80 \\
80 \\
85 \\
85 \\
80 \\
85 \\
80 \\
80 \\
800 \\
80 \\
80 \\
800 \\
85 \\
85 \\
85 \\
85 \\
85 \\
85 \\
80 \\
80 \\
80\end{array}$ & $\begin{array}{l}60 \\
55 \\
60 \\
65 \\
60 \\
60 \\
65 \\
65 \\
65 \\
60 \\
65 \\
60 \\
65 \\
60 \\
60 \\
65 \\
60 \\
60 \\
55 \\
55 \\
60 \\
60 \\
65 \\
60 \\
60 \\
60 \\
55 \\
55\end{array}$ & $\begin{array}{l}65 \\
65 \\
65 \\
60 \\
65 \\
65 \\
63\end{array}$ & $\bar{E}$ & $\begin{array}{l}10 \\
12 \\
12 \\
10 \\
10 \\
10 \\
10 \\
10 \\
10 \\
9 \\
10 \\
10 \\
10 \\
10 \\
9 \\
8 \\
9 \\
10 \\
10 \\
10 \\
9 \\
10 \\
10 \\
10 \\
10 \\
10 \\
10 \\
10\end{array}$ \\
\hline $\begin{array}{ll}M a d 1 a g \\
\text { del }\end{array}$ & $29 \quad 27$ & 27 & 82 & 60 & 63 & & 9 \\
\hline 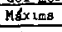 & $30 \quad 30$ & 28 & 85 & 65 & 65 & & 12 \\
\hline Minnime & $27 \quad 25$ & 27 & 80 & 55 & 60 & & $\theta$ \\
\hline
\end{tabular}

\begin{tabular}{|c|c|c|c|c|c|c|c|c|c|c|}
\hline \multicolumn{7}{|c|}{ Qbeserraterce لyece } & & \multicolumn{3}{|c|}{ Karre 1958} \\
\hline \multirow{2}{*}{ DLA } & \multicolumn{3}{|c|}{ 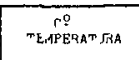 } & \multicolumn{3}{|c|}{ 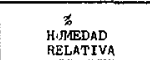 } & \multicolumn{3}{|c|}{ 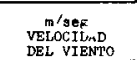 } & \multirow{2}{*}{$\begin{array}{l}\text { HORAS } \\
\mathrm{DE} \\
\text { SOL }\end{array}$} \\
\hline & \multicolumn{3}{|c|}{ 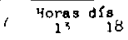 } & \multicolumn{3}{|c|}{$7{ }_{13}^{\text {Horas dia }}{ }_{18}$} & \multicolumn{3}{|c|}{${ }_{13}^{\text {Horas }} \mathrm{daA}_{18}$} & \\
\hline & & & & 80 & 75 & & 4 & 4 & 6 & 10 \\
\hline 3 & 25 & 28 & 26 & 83 & 73 & 78 & - & & 4 & 10 \\
\hline$\frac{3}{4}$ & \begin{tabular}{|l}
26 \\
27
\end{tabular} & $\begin{array}{l}29 \\
30\end{array}$ & ${ }_{27}^{27}$ & $\begin{array}{l}80 \\
80\end{array}$ & $\begin{array}{l}75 \\
75\end{array}$ & ${ }_{73}^{73}$ & $\overline{4}$ & $\overline{6}$ & ${ }_{8}^{2}$ & 9 \\
\hline 5 & 27 & 29 & 26 & 80 & 75 & 76 & & 6 & a & 10 \\
\hline 6 & 26 & 29 & 28 & 78 & 70 & 78 & & 8 & 10 & 8 \\
\hline 7 & 23 & 28 & ${ }_{27}^{26}$ & $\begin{array}{l}78 \\
85\end{array}$ & 73 & $\begin{array}{l}75 \\
80\end{array}$ & & $\overline{6}$ & $\overline{8}$ & 9 \\
\hline & 23 & 27 & 26 & 83 & 75 & 78 & & 2 & 4 & 9 \\
\hline 10 & 23 & 29 & 25 & 85 & 73 & 80 & - & - & - & 7 \\
\hline il & 22 & 28 & 27 & 84 & 73 & 78 & & 4 & 4 & 9 \\
\hline 12 & 23 & 28 & 27 & 85 & 70 & 73 & & $\overline{-}$ & 4 & a \\
\hline & 24 & 27 & 26 & 83 & 70 & 73 & 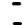 & $=$ & - & - \\
\hline 14 & $\begin{array}{l}23 \\
24\end{array}$ & ${ }_{27}^{28}$ & 25 & 80 & 710 & 73 & & $i$ & $\bar{z}$ & 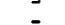 \\
\hline 16 & 23 & 28 & 26 & 85 & 73 & 74 & & 2 & 6 & 8 \\
\hline 17 & 24 & 28 & 26 & 85 & 70 & 73 & & 4 & 6 & 9 \\
\hline 18 & 24 & 28 & 26 & 83 & 70 & 73 & - & 4 & 6 & 9 \\
\hline 19 & 23 & 28 & 26 & 80 & 70 & 73 & & 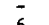 & - & 9 \\
\hline 20 & 24 & 29 & $\begin{array}{l}25 \\
25\end{array}$ & $\begin{array}{l}80 \\
78\end{array}-Y 2$ & $\begin{array}{l}70 \\
60\end{array}$ & $\begin{array}{l}71 \\
70\end{array}$ & & $\begin{array}{l}6 \\
4\end{array}$ & $\begin{array}{l}8 \\
6\end{array}$ & 9 \\
\hline 22 & 20 & 28 & 23 & 78 & 60 & 70 & & 4 & 8 & 20 \\
\hline $\begin{aligned} 23 \\
24\end{aligned}$ & 21 & 27 & $\begin{array}{l}24 \\
25\end{array}$ & $\begin{array}{l}78 \\
80\end{array}$ & $\begin{array}{l}63 \\
58\end{array}$ & $\begin{array}{l}65 \\
60\end{array}$ & $?$ & 4 & ${ }_{4}^{6}$ & $\begin{array}{l}10 \\
10\end{array}$ \\
\hline $\begin{array}{l}24 \\
25\end{array}$ & $\begin{array}{l}23 \\
21\end{array}$ & $\begin{array}{l}28 \\
28\end{array}$ & $\begin{array}{l}25 \\
25\end{array}$ & $\begin{array}{l}80 \\
80\end{array}$ & $\begin{array}{l}58 \\
58\end{array}$ & $\begin{array}{l}60 \\
65\end{array}$ & 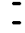 & $\begin{array}{l}4 \\
4\end{array}$ & $\begin{array}{l}4 \\
4\end{array}$ & $\begin{array}{l}100 \\
10\end{array}$ \\
\hline & & 27 & 24 & 80 & 60 & 65 & 2 & 4 & 4 & 10 \\
\hline 27 & 20 & 27 & 24 & $\begin{array}{l}85 \\
85\end{array}$ & $\begin{array}{l}65 \\
58\end{array}$ & $\begin{array}{l}68 \\
69\end{array}$ & - & $\overline{4}$ & $\frac{2}{6}$ & $\begin{array}{l}10 \\
10\end{array}$ \\
\hline 29 & 21 & 26 & 24 & 83 & 68 & 69 & - & 4 & 6 & 10 \\
\hline 30 & 22 & 26 & 24 & 80 & 70 & 68 & 4 & 4 & 6 & 10 \\
\hline & & & & & & & & & & \\
\hline Madiag & 24 & 28 & 26 & 84 & 70 & 73 & 3 & 4 & 6 & 8 \\
\hline 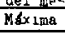 & 27 & 30 & 28 & 85 & 75 & 80 & 4 & 8 & 10 & 10 \\
\hline MPn1ma & 20 & 25 & 23 & 78 & 60 & 60 & & & & \\
\hline
\end{tabular}

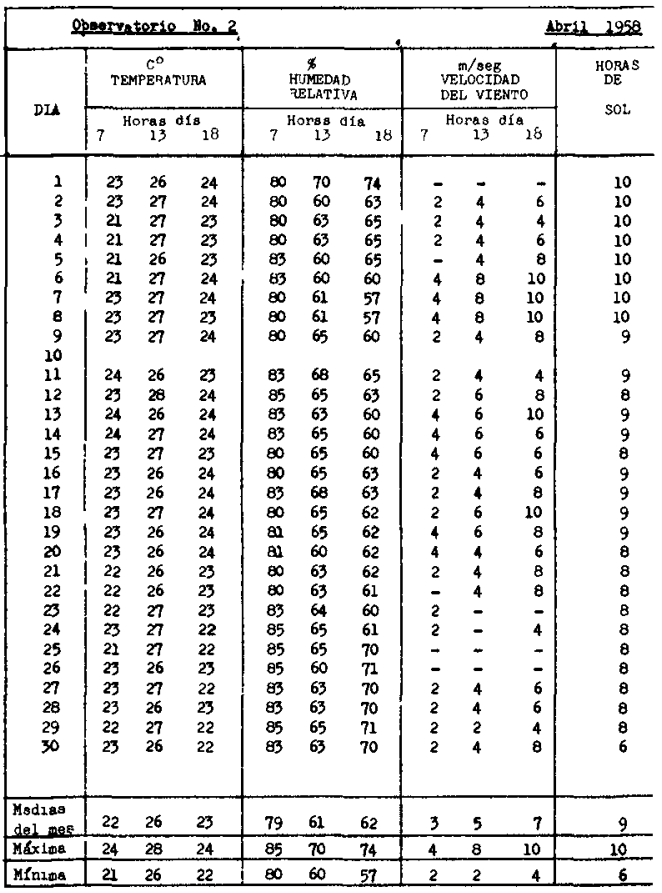




\title{
MEDICIONES DE ARENA EOLICA EXTRAIDA DE LA PLAYA DE SANTA ROSA POR DEFLACION
}

\author{
ANEXO, NO. 2
}

\begin{tabular}{|c|c|c|c|c|c|c|c|c|}
\hline & bervaterts & Nens & & & & & $\underline{\underline{\operatorname{mars}}}$ & \\
\hline & $\begin{array}{l}C^{\circ} \\
\text { TEMERA }\end{array}$ & & & 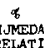 & & 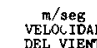 & & $\begin{array}{l}\text { HORAS } \\
\text { DS }\end{array}$ \\
\hline $1+\alpha$ & $7 \begin{array}{r}\text { Horas } \\
13\end{array}$ & & $7^{1}$ & $\begin{array}{r}\text { toras } \\
13\end{array}$ & ${ }_{18}{ }_{18}$ & $7{ }_{13}^{\text {Horas di }}$ & ${ }_{18}{ }_{18}$ & SOL \\
\hline & & & & & & & 4 & 10 \\
\hline 2 & $\begin{array}{ll}20 & 26 \\
20 & 26\end{array}$ & 22 & 85 & 65 & $\mathbf{B}_{\mathbf{0}}^{\infty}$ & $=2$ & 4 & 8 \\
\hline 4 & & 21 & 85 & 80 & $\infty$ & $=4$ & & 5 \\
\hline $\begin{array}{l}5 \\
6\end{array}$ & $\begin{array}{ll}19 & 25 \\
19 & 25\end{array}$ & ${ }_{21}^{21}$ & $\begin{array}{l}88 \\
87\end{array}$ & $\begin{array}{l}60 \\
60\end{array}$ & $\begin{array}{l}8 \infty \\
80\end{array}$ & $=\quad 4$ & & 5 \\
\hline & & 21 & 85 & $\begin{array}{l}\infty \\
63\end{array}$ & 70 & $=4$ & 6 & 10 \\
\hline 8 & 1925 & 21 & 80 & 60 & 70 & $-z_{4}^{4}$ & 4 & 10 \\
\hline 10 & $\begin{array}{ll}10 & 20 \\
18 & 23\end{array}$ & 19 & 85 & 65 & 85 & 4 & 6 & 8 \\
\hline 11 & 1923 & 29 & 85 & 65 & 84 & 22 & 4 & 6 \\
\hline $\begin{array}{l}122 \\
13\end{array}$ & $\begin{array}{ll}18 & 20 \\
18 & 20\end{array}$ & $\frac{21}{21}$ & $\begin{array}{l}92 \\
90\end{array}$ & $\begin{array}{l}80 \\
80\end{array}$ & $\begin{array}{l}72 \\
75\end{array}$ & $=4$ & $\frac{2}{6}$ & $\begin{array}{l}6 \\
6\end{array}$ \\
\hline 14 & $18 \quad 20$ & 21 & 87 & 80 & 75 & - & - & 2 \\
\hline 15 & $18 \quad 21$ & 20 & 85 & 65 & 75 & 3 & 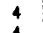 & \\
\hline 16 & 1720 & 21 & 90 & 67 & 75 & $\stackrel{2}{-}$ & 4 & 6 \\
\hline 18 & $\begin{array}{ll}18 \\
17 & 21\end{array}$ & $\begin{array}{l}20 \\
20\end{array}$ & 90 & 70 & 80 & - & $=$ & 4 \\
\hline 19 & $\mid \begin{array}{ll}17 & 21 \\
17 & 21\end{array}$ & $\begin{array}{l}20 \\
20\end{array}$ & 92 & $\begin{array}{l}70 \\
70\end{array}$ & ${ }_{\infty}^{\infty}$ & $=$ & - & ${ }_{6}^{4}$ \\
\hline a & $\begin{array}{lll}11 & 21 \\
18 & 21\end{array}$ & 20 & 90 & 70 & $\infty$ & $=$ & - & 4 \\
\hline 22 & $\begin{array}{ll}17 & 21\end{array}$ & 18 & 90 & 70 & 88 & $=$ & $=$ & $\overline{-}$ \\
\hline $\begin{array}{l}23 \\
24\end{array}$ & $\mid \begin{array}{ll}17 & 21 \\
17 & 20\end{array}$ & $\begin{array}{l}18 \\
19\end{array}$ & 垔0 & $\begin{array}{l}70 \\
72\end{array}$ & $\begin{array}{l}85 \\
80 \\
80\end{array}$ & $=$ & $=$ & - \\
\hline 25 & $17 \quad 20$ & 19 & 91 & 70 & $\infty$ & ? & $=$ & - \\
\hline 27 & $\begin{array}{lll}11 & 20 \\
28 & 20\end{array}$ & 19 & 90 & 70 & 年 & $=$ & $\rightarrow$ & 4 \\
\hline 28 & $27 \quad 21$ & 29 & 85 & 70 & 82 & - & - & \\
\hline 29 & 1721 & 19 & 83 & 70 & ${ }_{82}^{82}$ & - & $=$ & 6 \\
\hline 弯1 & $\mid \begin{array}{ll}217 \\
17 & 21\end{array}$ & 18 & 85 & 70 & 80 & $=$ & $=$ & 8 \\
\hline Modizas & $\begin{array}{|ll|}18 & 22 \\
\end{array}$ & 20 & 88 & 69 & 80 & 23 & 5 & 5 \\
\hline Máx & $\begin{array}{ll}20 & 26 \\
\end{array}$ & 23 & 92 & 80 & 90 & 2 & 6 & 20 \\
\hline MPn1ma & 1720 & 18 & 80 & 60 & 70 & 2 & 2 & 2 \\
\hline
\end{tabular}

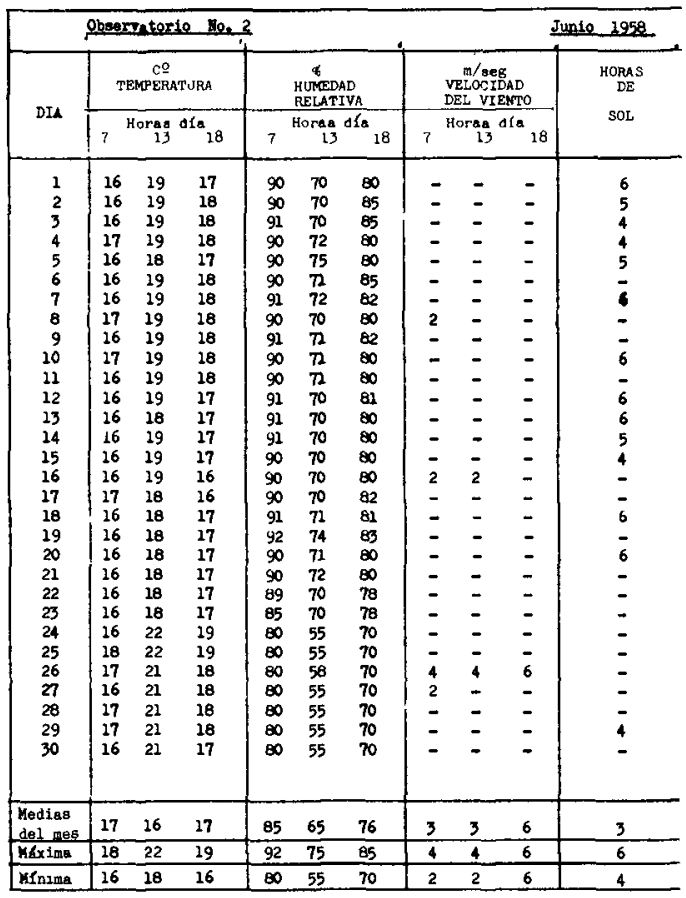

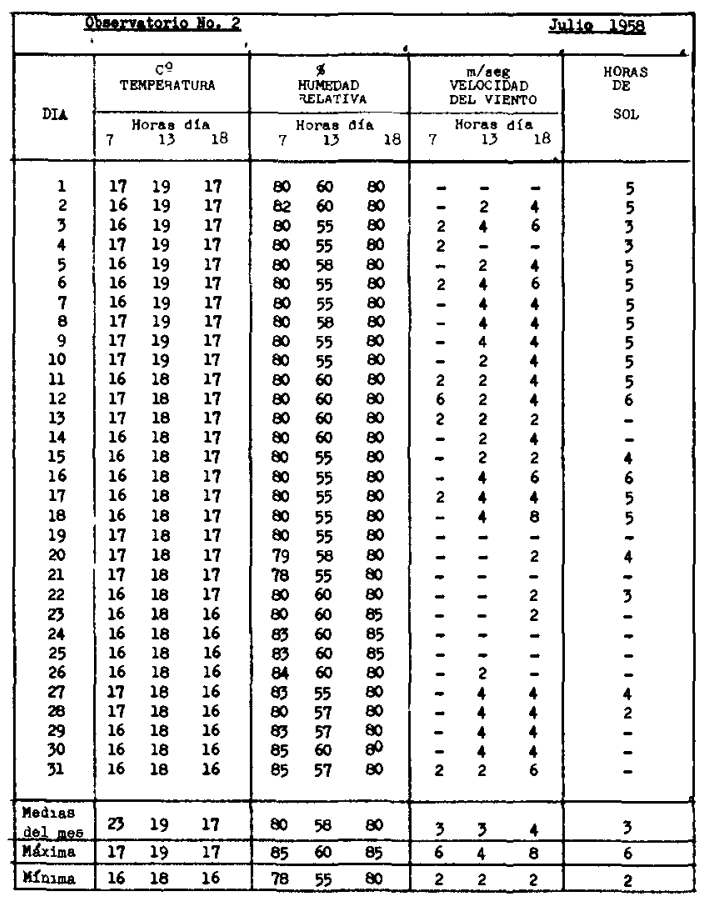

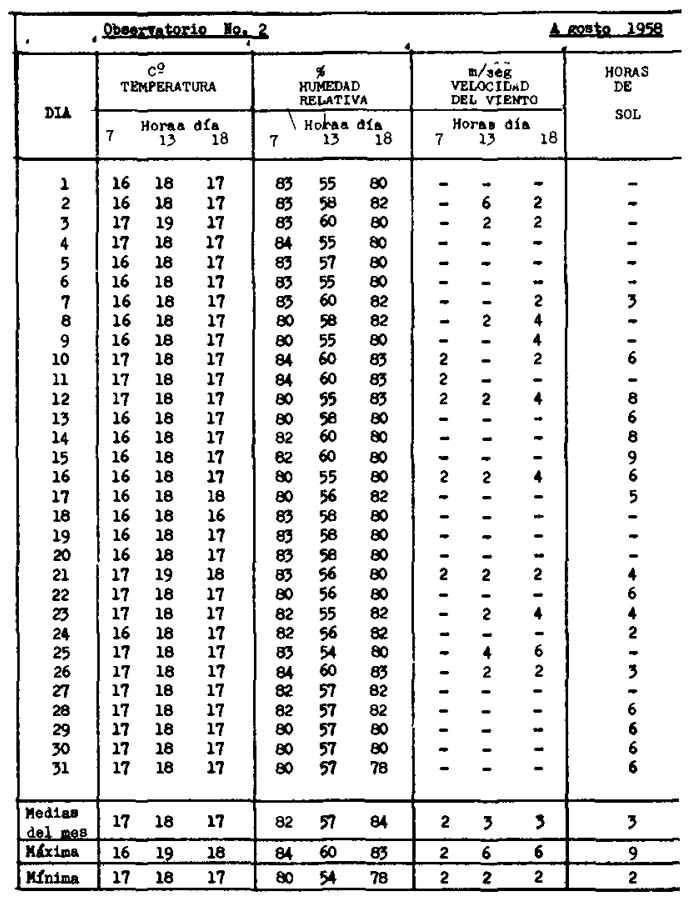




\title{
COASTAL ENGINEERING
}

\author{
ANEXO. INO. 2
}

\begin{tabular}{|c|c|c|c|c|}
\hline \multicolumn{3}{|c|}{ Obsernatorio Mo.? } & \multicolumn{2}{|c|}{ Setimance 2998} \\
\hline & TEMPERATVAA & 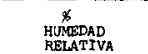 & 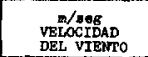 & $\begin{array}{c}\text { Homus } \\
\text { DE }\end{array}$ \\
\hline DIA & 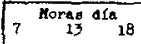 & 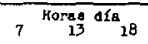 & $7^{\text {Horaag }}{ }_{13}^{\text {dfa }}{ }_{18}$ & sol \\
\hline $\begin{array}{l}1 \\
2 \\
3 \\
3 \\
5 \\
6 \\
6 \\
7 \\
8 \\
10 \\
11 \\
12 \\
12 \\
13 \\
14 \\
15 \\
17 \\
17 \\
19 \\
29 \\
20 \\
21 \\
22 \\
24 \\
23 \\
23 \\
26 \\
27 \\
29 \\
29 \\
30\end{array}$ & $\mid \begin{array}{lll}15 & 23 & 17 \\
16 & 23 & 17 \\
16 & 25 & 17 \\
16 & 25 & 17 \\
16 & 25 & 17 \\
16 & 25 & 17 \\
16 & 25 & 16 \\
16 & 26 & 16 \\
16 & 25 & 17 \\
16 & 24 & 16 \\
16 & 23 & 17 \\
16 & 23 & 17 \\
16 & 23 & 16 \\
15 & 25 & 17 \\
16 & 25 & 18 \\
16 & 25 & 17 \\
16 & 25 & 16 \\
16 & 24 & 17 \\
16 & 24 & 16 \\
16 & 24 & 16 \\
15 & 25 & 16 \\
15 & 25 & 16 \\
15 & 21 & 16 \\
16 & 21 & 16 \\
16 & 20 & 16 \\
16 & 20 & 27 \\
15 & 21 & 17 \\
16 & 21 & 17 \\
16 & 21 & 17 \\
16 & 21 & 17\end{array}$ & 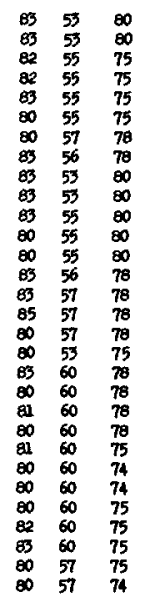 & $\begin{array}{lll}2 & 4 & 6 \\
2 & 4 & 6 \\
2 & 4 & 6 \\
2 & 2 & 2 \\
\vdots & 2 & 2 \\
\vdots & 2 & 2 \\
\vdots & \vdots & \vdots \\
\vdots & 2 & 2 \\
\vdots & 2 & 2 \\
\vdots & \vdots & \vdots \\
\vdots & \vdots & \vdots \\
\vdots & \vdots & 2 \\
\vdots & \vdots & \vdots \\
\vdots & 2 & 2 \\
\vdots & 2 & - \\
\vdots & \vdots & \vdots \\
\vdots & \vdots & \vdots \\
\vdots & \vdots & \vdots \\
\vdots & \vdots & \vdots \\
2 & 4 & 4\end{array}$ & $\begin{array}{l}6 \\
5 \\
5 \\
6 \\
6 \\
6 \\
6\end{array}$ \\
\hline 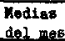 & $\begin{array}{ll}25 & 23 \\
\end{array}$ & $\begin{array}{lll}79 & 55 & 75\end{array}$ & 22 & \\
\hline & 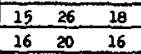 & $\begin{array}{lll}85 & 60 & 80 \\
80 & 53 & 74 \\
\end{array}$ & $\begin{array}{|lll|}2 & 4 & 6 \\
2 & 2 & 2 \\
\end{array}$ & \\
\hline
\end{tabular}

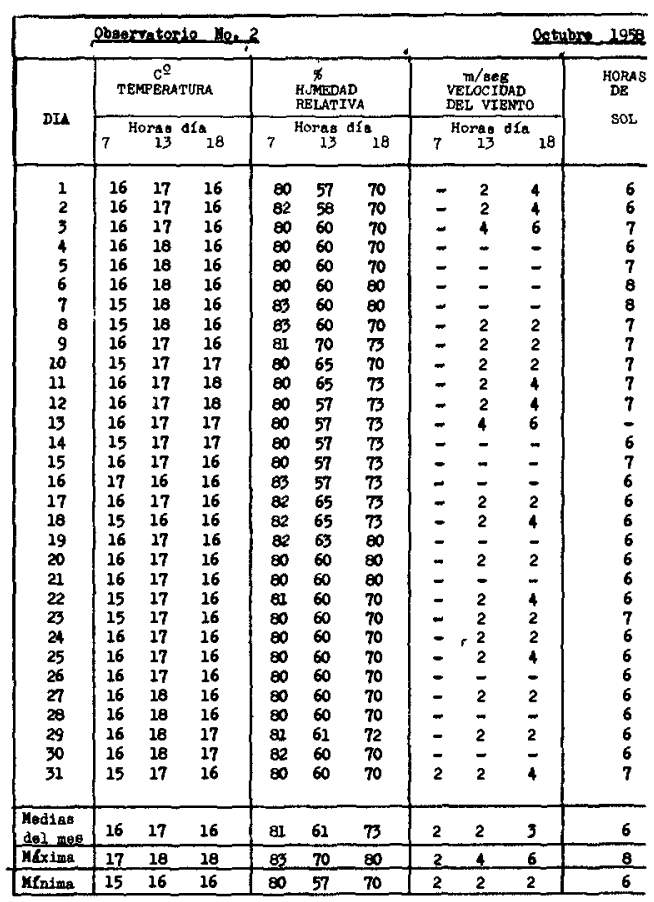

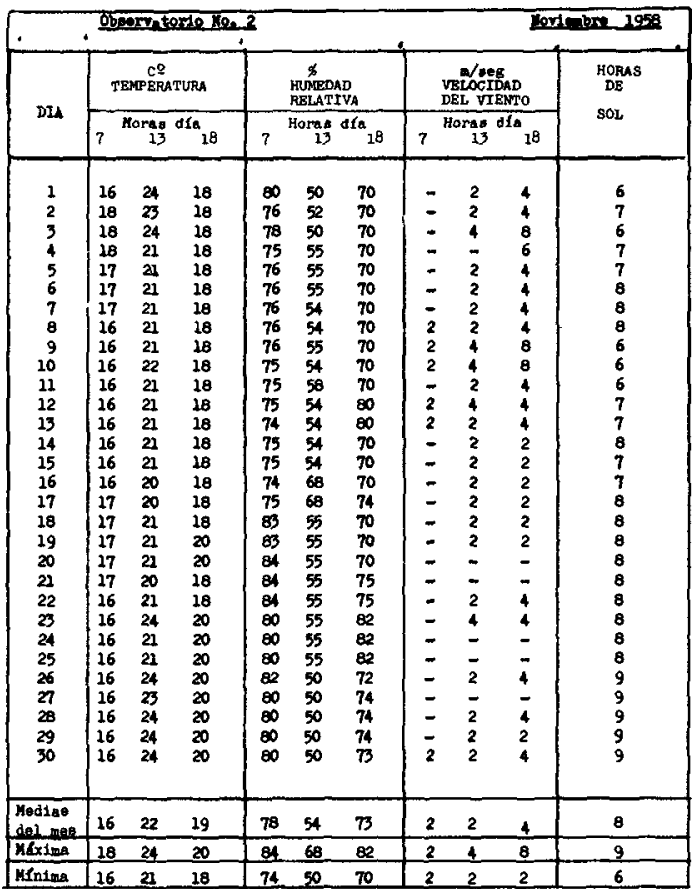

\begin{tabular}{|c|c|c|c|c|c|c|c|c|}
\hline \multicolumn{6}{|c|}{ 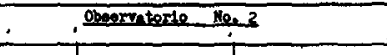 } & \multicolumn{3}{|c|}{2 Dicherese 295} \\
\hline \multirow{2}{*}{ DIA } & \multicolumn{2}{|c|}{ TEAPRRATURA } & \multicolumn{3}{|c|}{ 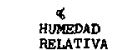 } & \multicolumn{2}{|c|}{$\begin{array}{l}\text { m/aeg } \\
\text { YELOCGDAD } \\
\text { DEL VIEATOO }\end{array}$} & \multirow{2}{*}{$\begin{array}{l}\text { HORA } \\
\text { DE } \\
\text { SOL }\end{array}$} \\
\hline & $7{ }_{13}^{\text {Horas }}$ & ${ }_{18}$ & & ${ }_{13}^{\circ}$ & 15 & , Horag dif & & \\
\hline $\begin{array}{r}1 \\
2 \\
3 \\
4 \\
5 \\
6 \\
7 \\
8 \\
9 \\
10 \\
11 \\
12 \\
13 \\
14 \\
15 \\
16 \\
17 \\
18 \\
19 \\
20 \\
21 \\
22 \\
23 \\
24 \\
25 \\
26 \\
27 \\
28 \\
29 \\
30 \\
31\end{array}$ & $\begin{array}{ll}19 & 21 \\
19 & 21 \\
19 & 21 \\
19 & 20 \\
19 & 20 \\
19 & 20 \\
18 & 20 \\
19 & 24 \\
18 & 24 \\
18 & 24 \\
19 & 24 \\
19 & 24 \\
19 & 22 \\
19 & 22 \\
19 & 21 \\
19 & 21 \\
18 & 22 \\
18 & 22 \\
18 & 20 \\
18 & 22 \\
18 & 22 \\
18 & 21 \\
18 & 20 \\
18 & 22 \\
18 & 22 \\
18 & 21 \\
19 & 21 \\
19 & 20 \\
18 & 20 \\
18 & 20 \\
18 & 20\end{array}$ & $\begin{array}{l}22 \\
22 \\
22 \\
211 \\
21 \\
22 \\
21 \\
20 \\
20 \\
20 \\
20 \\
20 \\
23 \\
23 \\
23 \\
23 \\
20 \\
20 \\
19 \\
20 \\
20 \\
19 \\
19 \\
20 \\
20 \\
20 \\
20 \\
21 \\
21 \\
21 \\
21\end{array}$ & $\begin{array}{l}85 \\
85 \\
85 \\
85 \\
85 \\
80 \\
80 \\
80 \\
80 \\
80 \\
80 \\
75 \\
71 \\
75 \\
75 \\
75 \\
75 \\
80 \\
80 \\
80 \\
75 \\
75 \\
75 \\
75 \\
77 \\
70 \\
70 \\
70 \\
76 \\
75 \\
75 \\
75\end{array}$ & $\begin{array}{l}72 \\
72 \\
72 \\
72 \\
73 \\
73 \\
73 \\
53 \\
53 \\
52 \\
52 \\
53 \\
53 \\
53 \\
53 \\
52 \\
63 \\
63 \\
70 \\
52 \\
52 \\
53 \\
53 \\
54 \\
54 \\
54 \\
54 \\
55 \\
54 \\
54 \\
54\end{array}$ & $\begin{array}{l}70 \\
70 \\
70 \\
70 \\
70 \\
70 \\
70 \\
70 \\
58 \\
58 \\
76 \\
76 \\
76 \\
65 \\
65 \\
65 \\
65 \\
72 \\
72 \\
72 \\
72 \\
72 \\
71 \\
70 \\
70 \\
70 \\
70 \\
70 \\
70 \\
70 \\
70 \\
70\end{array}$ & 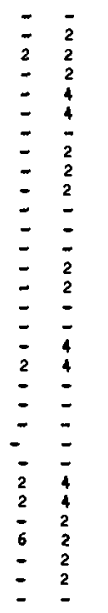 & $\begin{array}{l}-2 \\
4 \\
4 \\
6 \\
6 \\
- \\
2 \\
4 \\
- \\
- \\
\\
4 \\
4 \\
- \\
\\
8 \\
- \\
\\
- \\
- \\
6 \\
8 \\
4 \\
4\end{array}$ & $\begin{array}{r}10 \\
10 \\
10 \\
12 \\
9 \\
10 \\
12 \\
10 \\
10 \\
12 \\
12 \\
10 \\
8 \\
8 \\
8 \\
6 \\
4 \\
10 \\
10 \\
12 \\
10 \\
10 \\
10 \\
10 \\
12 \\
9 \\
9 \\
9 \\
9 \\
10 \\
9\end{array}$ \\
\hline & $19 \quad 21$ & 21 & $\pi 7$ & 59 & 69 & $2 \quad 2$ & 3 & 10 \\
\hline & $19 \quad 24$ & 23 & 85 & 73 & 76 & $6 \quad 4$ & & 12 \\
\hline $\sin$ & $18 \quad 20$ & 19 & 70 & & & $2 \quad 2$ & & \\
\hline
\end{tabular}




\section{MEDICIONES DE ARENA EOLICA EXTRAIDA DE LA PLAYA DE SANTA ROSA POR DEFLACION}

ANEXO NO. 3

\section{SECCION - AB}

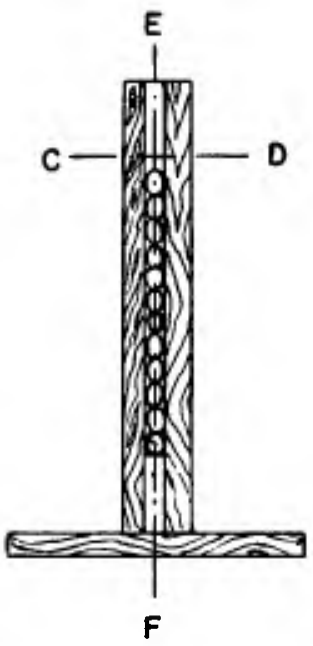

SECCION - CD
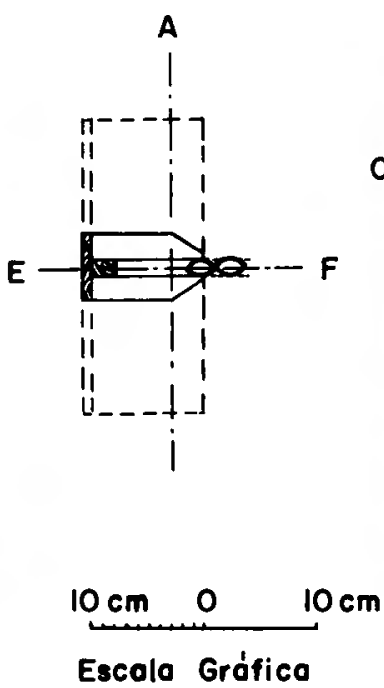

Fig. 1
SECCION-EF

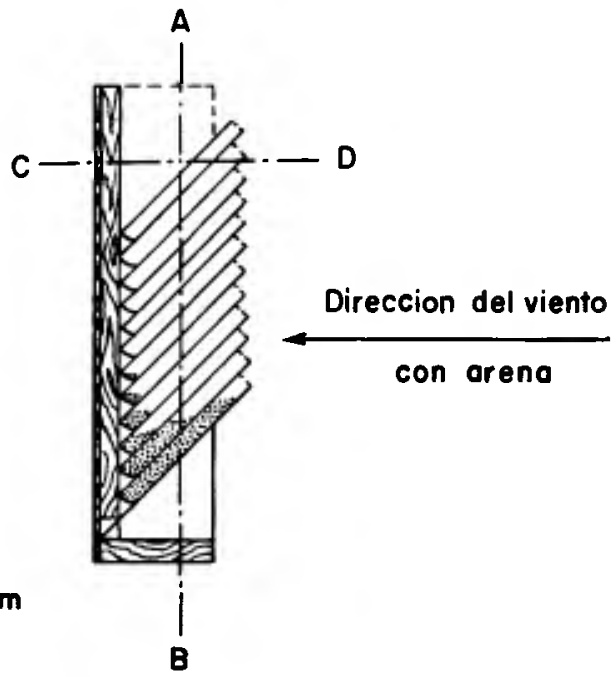

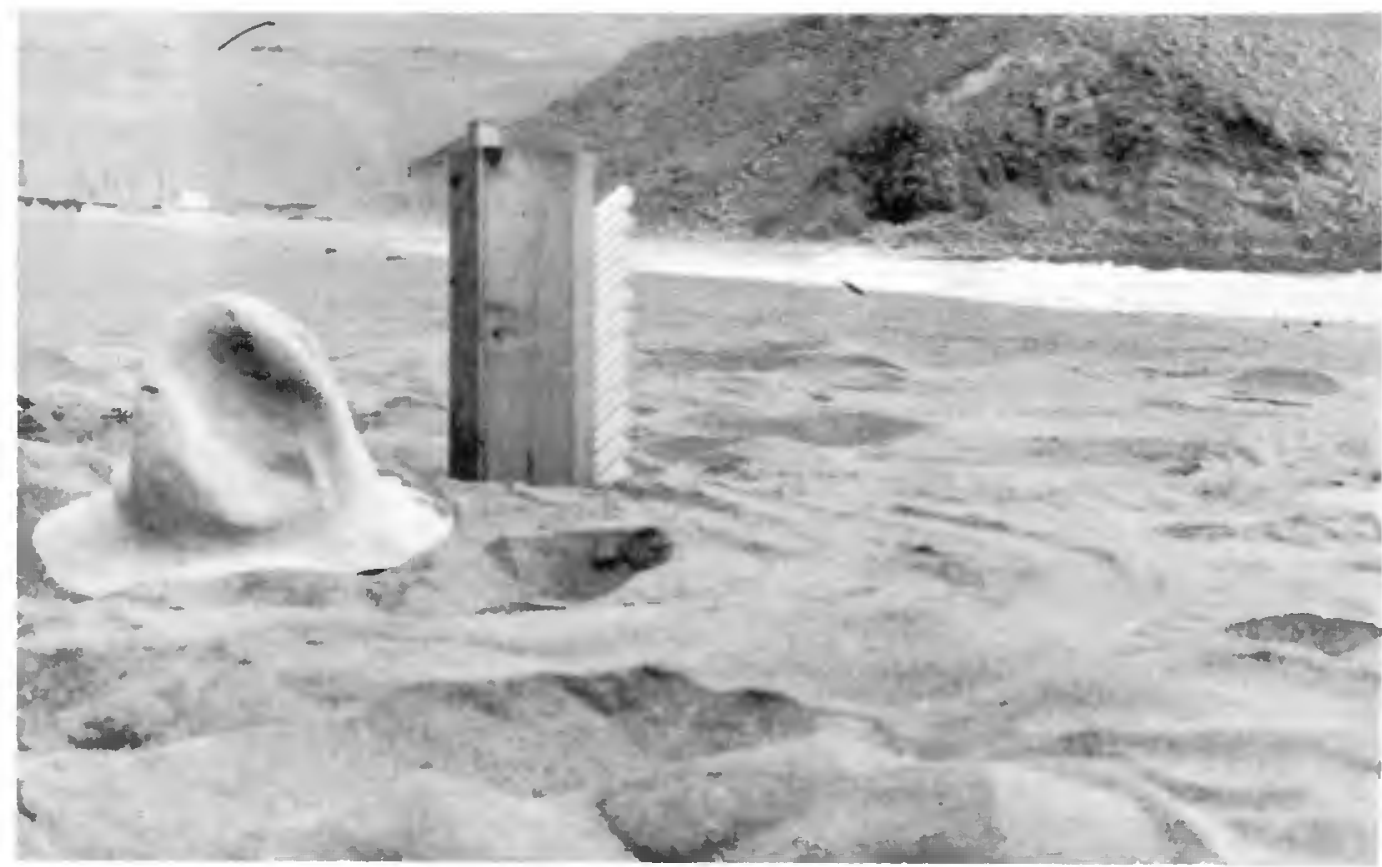

Foto No. 1. Arenómetro BZ o de Zocalo puesto en estacion. Fn Ia Playa de Santa Rosa. 
COASTAL ENGINEERING

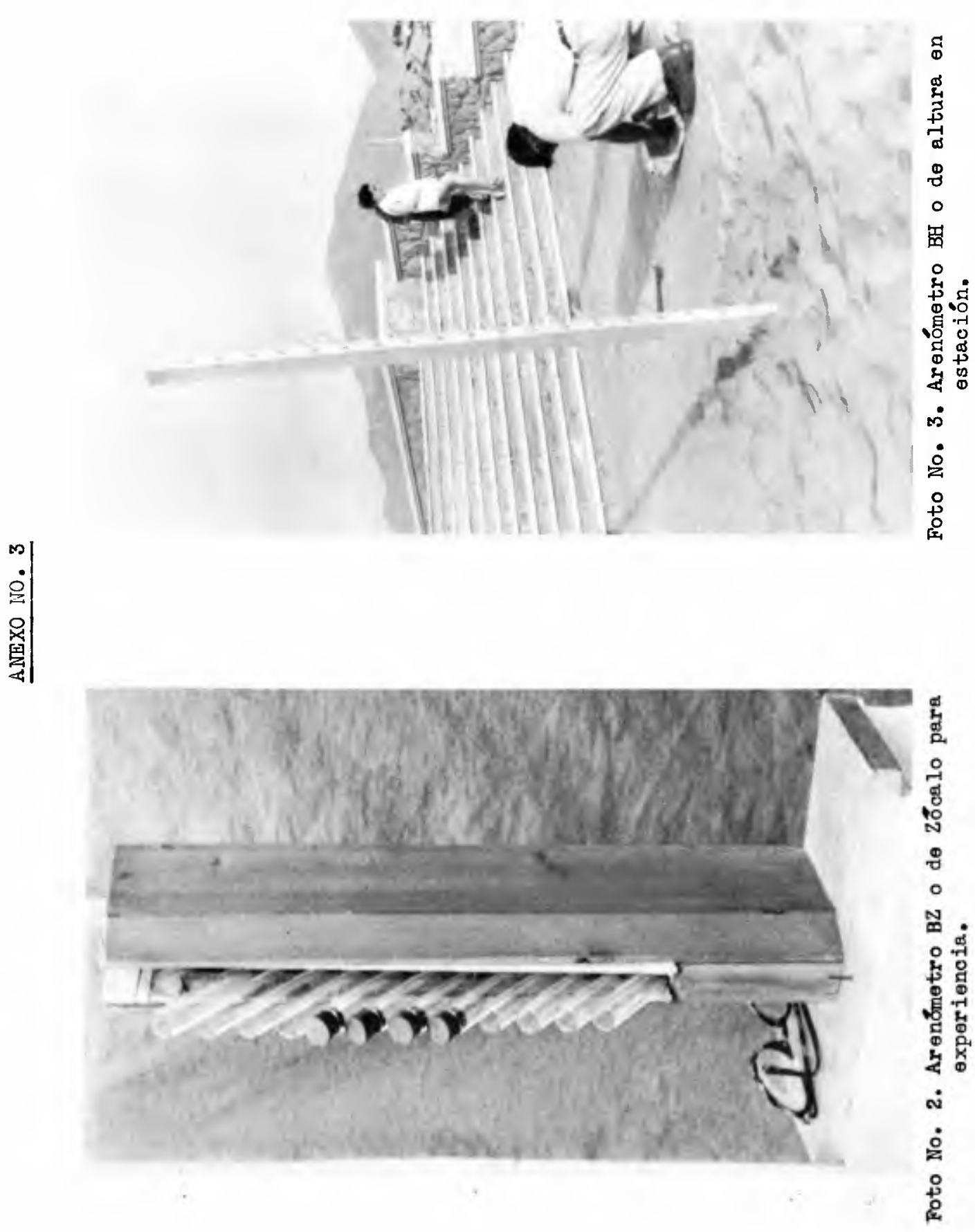




\title{
MEDICIONES DE ARENA EOLICA EXTRAIDA DE LA PLAYA DE SANTA ROSA POR DEFLACION
}

\author{
A. NEXONO. 4
}

Mensuras individuals con arenometros "BZ" O Broggi de Zocalo

SRPBRIISYIO I

- - LUeari Playa de Santo Rose, punto A dol pleso el 20.000 do Lnoxo No, I

b. - PDCHAs (14 1.58) Cotorce de Enero do 1958

0 - DITCS De hatesas a

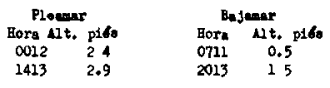

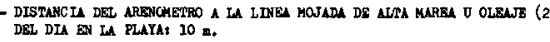

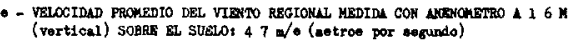

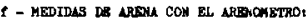

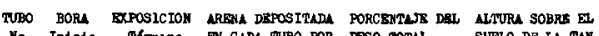

VN CADA TUBO FOR PESO TOTAL SUELO DE IA TASVIENTO

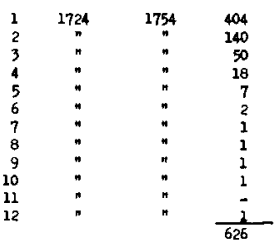
${ }_{22.37}^{64.53}$ (3)

$\frac{13.20}{10000}$

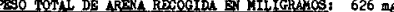
TDPRO TOTAL DE OBSERYACION: 30 ainutoa

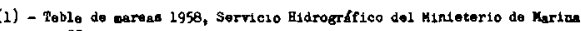

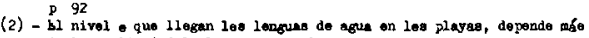

(2) - bl nivol e qua liegan loo longuas de ague on

(3) - Didínetro interior de cada tulo de prueba: $13 \mathrm{am}$, y exterior $15 \mathrm{~mm}$, longr tud: $148 \mathrm{~mm}$.

\section{XPER MEMTO: U}

- - Lochri plave de Sante rose, punto A dol plano el 20,000 do Anexo Ho 1 D - FECHA (20-2-58) Vounte do Pobreto de 1958

o. - DATCS DE MAFRHS EN

\begin{tabular}{|c|c|c|c|}
\hline & 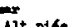 & & \\
\hline & & & 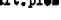 \\
\hline $\begin{array}{l}0654 \\
1920\end{array}$ & $\begin{array}{l}25 \\
3.0\end{array}$ & $\begin{array}{l}0115 \\
1251\end{array}$ & $\begin{array}{l}09 \\
08\end{array}$ \\
\hline
\end{tabular}

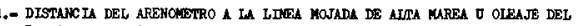
DIA EN LA PTAYA $30 \mathrm{x}$

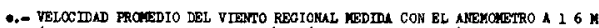
(Vortiosl SORRE EL SUBIO 5 m/oos (motros por sogudo).

t.- MEDDAN DE AREMA CON EL ARENONETTO

TUBO HOFA EXPOSICIOH ARERA DEPOSITADA PORCENTAS DEL ALATRA SOBRB

Ho InIeio TGralro ENA CADA TUBO PCR FESO TOTAL SUELO DE LA TAN-

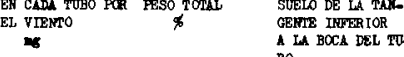

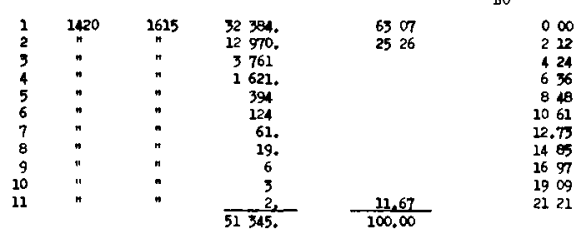

PESO TOTAL DE ARENA RECOCIDA EH MLLIGRAMOS 51345 TIEMPC TOTAL DE OBSERTACION 115 mimuton

Nota: En esto miano día, do 1630 - 1700 hubo un viento do $4.7 \mathrm{~W} / \mathrm{s}$. $05 \mathrm{M}$ (do oltitud) So introdujo mortionlesente on 12 srops al lado dol ine 1 cm del advel del oxolo $y$ on modia hore se recogí $212856 \mathrm{mg}$.

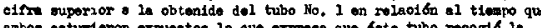

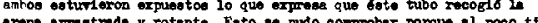

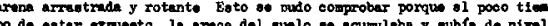

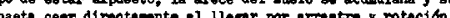

EXPERTMENTO II

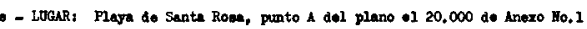
b.- FECE: (20-1-50) 7ointe do thoro do 1958

\begin{tabular}{|c|c|c|c|}
\hline \multirow[t]{2}{*}{$\begin{array}{c}\text { - DATOS DE MARLAS EM } \\
\text { CALLO (1) }\end{array}$} & $\underset{\text { Bore }}{\text { P1oneme }}$ & \multicolumn{2}{|c|}{$\begin{array}{l}\text { Beganar } \\
\text { Hoxe Alt.p16n }\end{array}$} \\
\hline & $\begin{array}{l}0554 \\
1849\end{array}$ & $\begin{array}{l}0046 \\
1155\end{array}$ & $\begin{array}{l}1.0 \\
0.3\end{array}$ \\
\hline
\end{tabular}

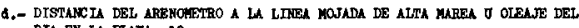
DIA ER IA PTATh; 10 .

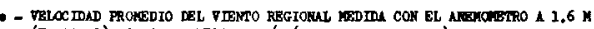

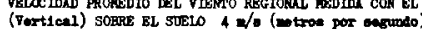

P - MEDTDAS DE ARETU COH RL ARERONGTRO,

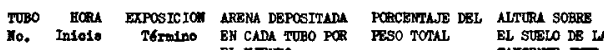

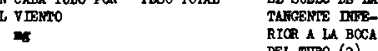

$\begin{array}{cccccc}1 & 1500 & 1818 & 35 & 61.40 & 6.00 \\ 2 & " & n & 15 & 26.32 & 8.12 \\ 3 & " & n & 5 & & 10.24 \\ 4 & " & n & 1 & & 1236 \\ 5 & " & n & \frac{2}{57} & -\frac{22.28}{100.00} & 14.49\end{array}$

PESO TOTAL DE KRERA BECOGDA EN MILTGRUMOS 57 TIDAPO TOTAL DE OBSERTACTON: 20 mimuton

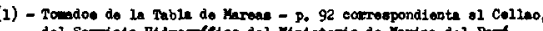
del Serviolo Fidrografios del Minieterio de Morine del pard.

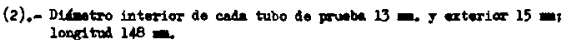

EXPGRDTEMOZ: II

- LUGRr playe de Sante Roea, punto a del plano el 20,000 no 1

b - FECFA (21-2-5e) Vointiuno de Febrero do 1958

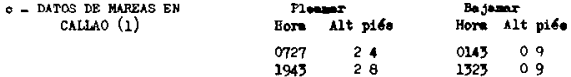

a - DISTAMC IA DEL AREMOHETRO A LA LIRFA MOJADA DE ALTA MAREA O OTEATE DEL DTA EM IA PLAYS 10 .

- - VFLOCIAD PRONEDIO DEL VIENTO (no so mid16) (2)

I - MEDIDAS DF AREM CON EL AREHOHETRO

TUBO BORA EXPOSICJON APENA DEPOSTTADA PRRCENIASB DEL ALTURA SOBRE EI

Ho. Inioio TGTTINO EN CADA TOBO POR PESO TOTAL SLETO DE LA TAKL

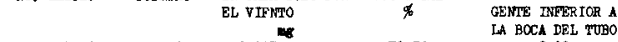

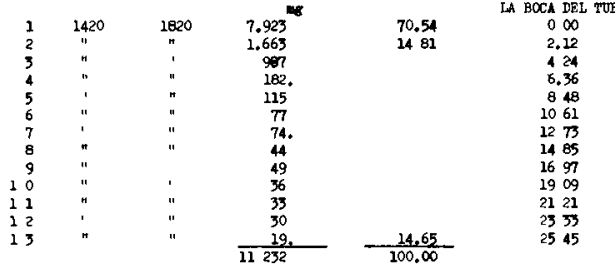

FESO TOTAL DE ARENA RECOCIPA BN MILIERAMOS 11232

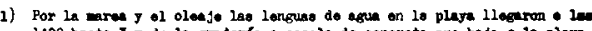

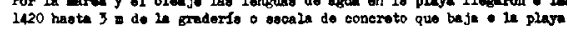

(2) Habia viento poco intenso poro oon retinges fuertes 


\title{
COASTAL ENGINEERING
}

\author{
ANEXO NN. 4
}

\section{EXPFRDAEMTO I I}

a - LUGar playa de Sarta hosa

b - Facku (5-3-58) Canco da Marzo da 1958

\begin{tabular}{|c|c|c|c|c|}
\hline \multirow[t]{2}{*}{$\begin{array}{c}\text { 0.- DatOS DE Marea EA } \\
\text { CALLAO }\end{array}$} & \multicolumn{2}{|c|}{ Pleamar } & \multicolumn{2}{|c|}{ Bayear } \\
\hline & $\begin{array}{l}0506 \\
1740\end{array}$ & $\begin{array}{l}20 \\
3.5\end{array}$ & $\mathfrak{u n}_{\infty}$ & $\begin{array}{ll}03 \\
0 & 3\end{array}$ \\
\hline
\end{tabular}

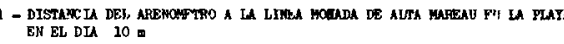

- - TELOCIDAD PRONEDIO DEL, VEEMTO A 28 ON SOBRE EL SUSLO $3 w / \bullet$

1 - MEDDDAS CON EL ARERONETRO

TUBO HORA ERPOSICION ARFRA DEPOSTTADA PORCENTAJR DEL AUTURA SOBRE EL

No. Into10 TKraino EK CADA TTBO POR PESO TOTAL STRLO DE LA TAM

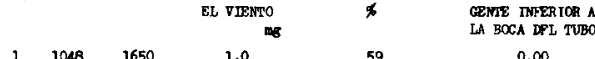

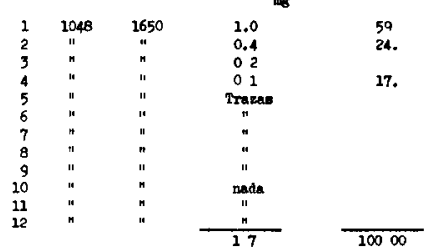

EESO TOTAL DE ARENA RECOGDA EN ULLCHAMOS 17

TIBMPO TOTAL DE CONSERVACIOTR O602

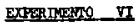

- - LJGRrs Playa de Senta Roma, punto a dal plano el 20.000 de Anomo 1

b.- FECEAS (17.5 58) Diectosia te de Marso de 1958

\begin{tabular}{|c|c|c|c|c|}
\hline \multirow{3}{*}{$\begin{array}{c}0 \text { - DATOS DE MAREAS EN } \\
\text { CALLAO }\end{array}$} & \multirow{2}{*}{\multicolumn{2}{|c|}{ Fleame }} & \multirow{2}{*}{\multicolumn{2}{|c|}{$\begin{array}{l}\text { Bajeanr } \\
\text { Hora }\end{array}$}} \\
\hline & & & & \\
\hline & $\begin{array}{l}0421 \\
1046\end{array}$ & $\begin{array}{l}2 \\
3\end{array}$ & $\begin{array}{l}1016 \\
2312\end{array}$ & $\begin{array}{l}0.8 \\
09\end{array}$ \\
\hline
\end{tabular}

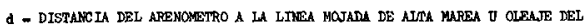
Dia en ia puay 10 .

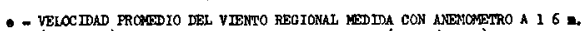

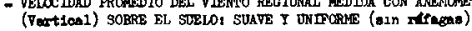

1,- MEDDDAS CON BL ARENOMETRO

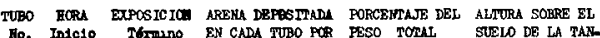

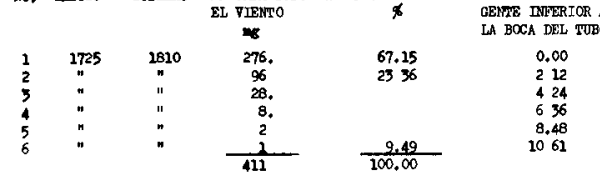

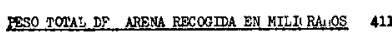
TIEMPO TORAL DE OBS BVACIOMY, 45 minutos

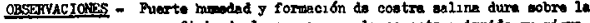

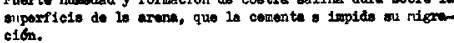

\section{EXPER DIEMTO}

- LOGAR, Plays de Santa Rosa, punto A dal plano al 20.000 da Anezo \$lo, 1

b.- FECBA: (17-4-58) Dicisiate da Abr1l da 1959

C- DATOS DE MAREAS EN

\begin{tabular}{cccc} 
Plamar & \multicolumn{2}{c}{ Bajarax } \\
Hore A1t.p16s & Horat & A1t p16s \\
0511 & 2.8 & 1112 & 11 \\
1701 & 2.7 & 2320 & 0.7
\end{tabular}

b.- FECHA: (5-48) c noo de Abml de 1958

\begin{tabular}{|c|c|c|c|c|}
\hline \multirow[t]{2}{*}{$\begin{array}{c}\text { 0.- DATOS DE MAREAS EN } \\
\text { CALLAN }\end{array}$} & \multicolumn{2}{|c|}{ Ploums } & \multicolumn{2}{|c|}{ Bajemar } \\
\hline & $\begin{array}{l}0632 \\
2895\end{array}$ & $\begin{array}{l}3.5 \\
3.1\end{array}$ & $\begin{array}{l}0009 \\
1244\end{array}$ & $\begin{array}{l}0.2 \\
0.6\end{array}$ \\
\hline
\end{tabular}

d.- DISTANCIA DER

$2035 \quad 0.6$

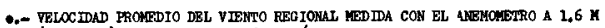

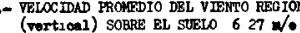

1.- MEDLDAS CON EL ARE'TOHEYRO

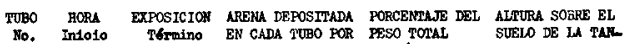

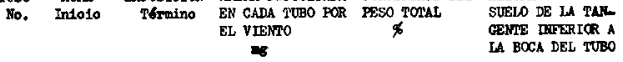

\begin{tabular}{|c|c|c|c|c|c|}
\hline & & & $g$ & & LA BOCA DEL T \\
\hline 1 & 1230 & 1830 & $\begin{array}{r}28,632 . \\
8640\end{array}$ & 50.75 & $\begin{array}{l}400 \\
6.12\end{array}$ \\
\hline$\frac{2}{5}$ & " & & $\begin{array}{l}8.640 \\
3.960\end{array}$ & & $\begin{array}{l}6.22 \\
8.24\end{array}$ \\
\hline 4 & $n$ & ، & 2.000 & & 10,36 \\
\hline & " & & 1.117 & & 1248 \\
\hline & n & " & 665 & & 14.61 \\
\hline & $"$ & " & 440. & & 16.73 \\
\hline 8 & " & . & 345. & & 18.05 \\
\hline 9 & n & ( & 278 & & 2097 \\
\hline 10 & $n$ & $"$ & 227 & & 2309 \\
\hline 11 & $n$ & & 168. & & 25.21 \\
\hline 12 & n & " & $\frac{145}{731}$ & 25.73 & $=733$ \\
\hline
\end{tabular}

FESO TOTAL_DE ARENG BDCOGDA EN KILIGRAMOS 36.731

TIEMPO TOZAL DE OBSERVAC YOH 360 minuto" d - DISTANC IA DEL ARENOWETRO A LA LINEA MOJADA DE AITA MAREA U OTEATE DFL DIA

EN La PLAYa 10 a

-.- TELOCTDA PROMBDiO DFL TIENTO REGTONAL MFDDDA CON EL, ANEMONETRO A $16 \mathrm{~K}$

(Vortion1) SOBQE EL SUELO no as tood

f.- MEDDASA CON \&L ARENOHETRO

TUBO HORA EXPOSICION AREMA DEPOSITADA FORCENTAJE DEL AITURA GOPRE EL

Bo. Insoio Tórmia EN CADA TUBO POR FESO TOMAL SUELO DE LA TAN-

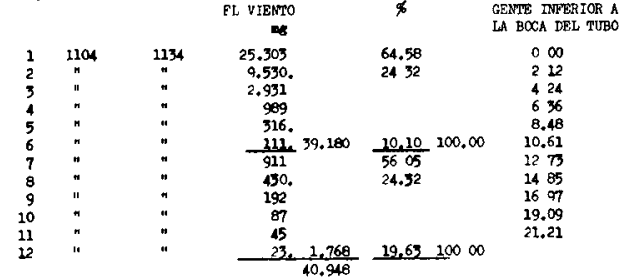

FSO TOCAL DE ARRNA RECOGTD EII MILIGRAMOS 40.948 TIDMPO TOSAL LE OASERVAC TON

a - dal tubo No, 1 sl ho $6 \quad 50$ minuto

Nota - So taparon 108 tubos 1 \$ 16 a lon 30 minutos pomu hablan rectbido

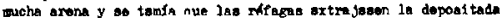




\section{MEDICIONES DE ARENA EOLICA EXTRAIDA DE LA PLAYA DE SANTA ROSA POR DEFLACION}

\section{ANEXO HO. 5}

Nensuras con 2, 3, y 4 Arenómetros $B Z$

Experimento I

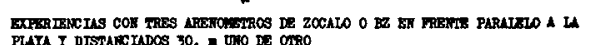

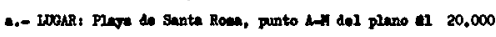

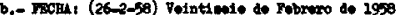

o.- Daros dE Maras as

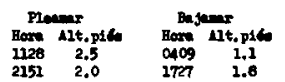

$\begin{array}{llll}1128 & 2.5 & 0409 & 1.1 \\ 2151 & 2.0 & 2727 & 1.6\end{array}$

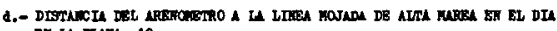

EX IA PIAYi; 10 a.

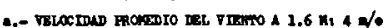

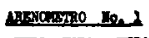

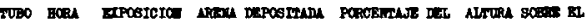

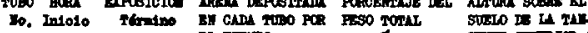

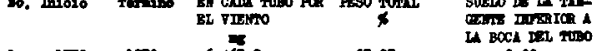

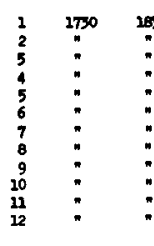

$\begin{array}{ll}6.465 .8 & 65.95 \\ 2.496 .6 & 25.47\end{array}$

241.0

241.0
80.0

23.6
9.6
5.5
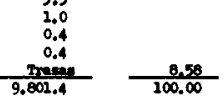

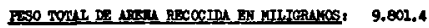

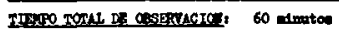

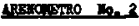

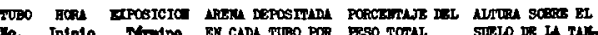

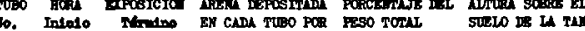

0.00

2.12
4.24
6.36

8.40
10.61
12.73

16.97

21.21

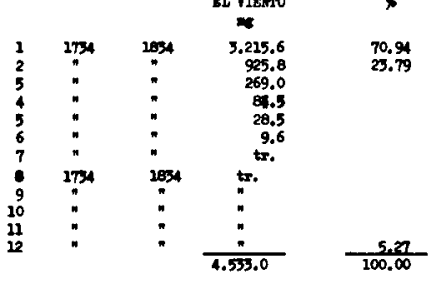
LA BOCA DET TOBO

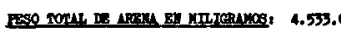

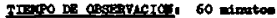

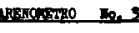

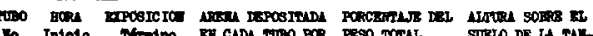
0.00
2.12
4.24
6.36
0.46
10.61

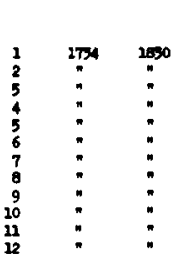
EI CAD TUD 5.651 .3
1.009 .1 400.0
19.6 72.5
26.1
10.7
4.5
1.5
0.9 2races

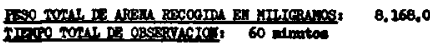

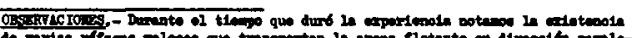

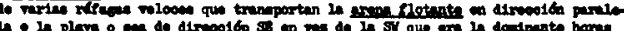

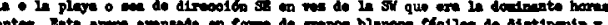

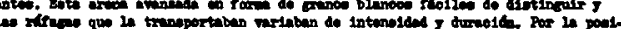

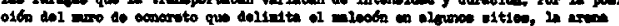

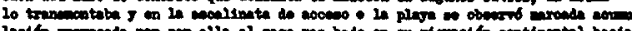

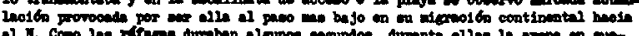

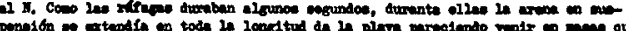

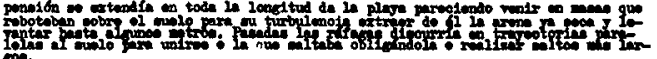

Experimento II

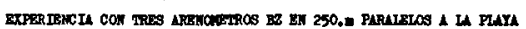

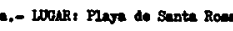

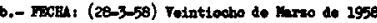

- - DATres ie mareas

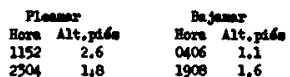

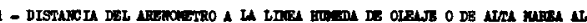

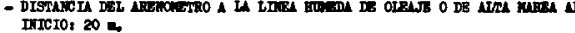

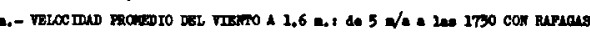

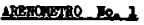

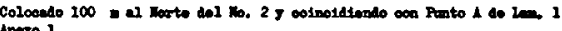

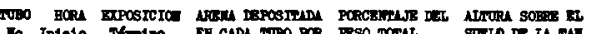

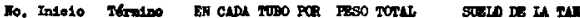

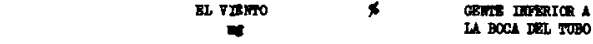

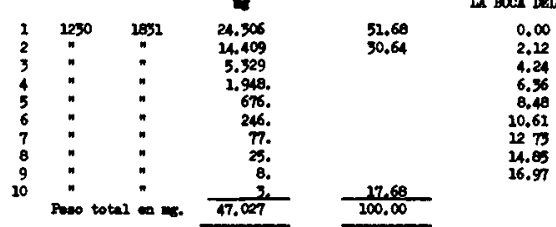

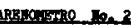

Colocodo(1000 al sur) dol No. 1

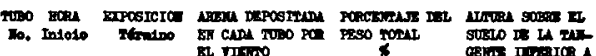

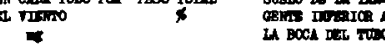

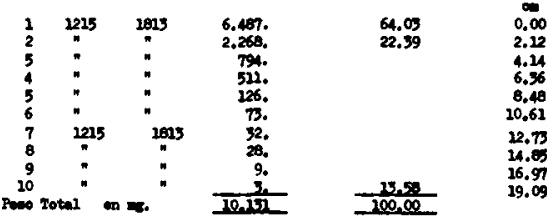

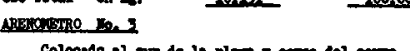

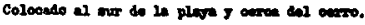

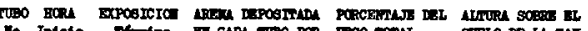

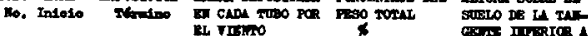

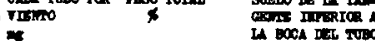

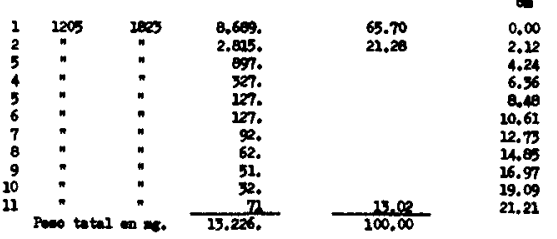
EXPRTiano II

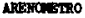

I

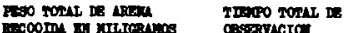

$47.027=\quad \times 614$

$10.171 "$

III

13.226 " 


\section{COASTAL ENGINEERING}

\section{ANEXO HO. 5}

Experimento No. III

EXPERIENCIA CON CUATRO BZ PARALELOS A IA PLAYA Y A PART IR DE IA ESCALINATA AL SUR, DISTANC IADOS 30.= UNO DE ONRO

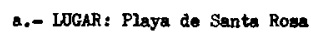

d.- DISTA NCIA DE LOS ARENONETROS A LA LINEA HUMEDA DE OLFAJE O DF ALTA MAREA AL INICIO: 15 .

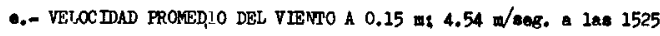
ARBNONDTRO No. I

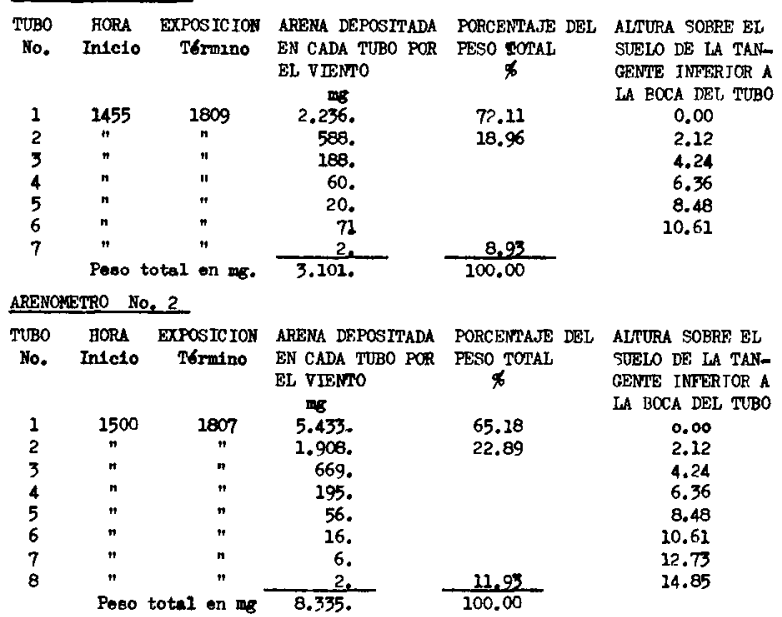

ARPNONETRO NO, 3

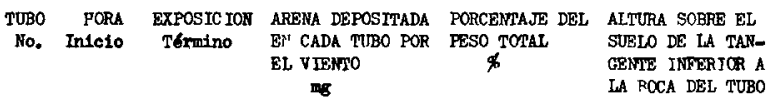

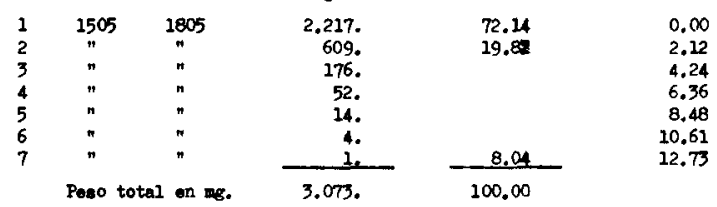

\section{ARENOY,ETRO NO, 4}

\begin{tabular}{|c|c|c|c|c|c|}
\hline $\begin{array}{l}\text { TUBO } \\
\text { No. }\end{array}$ & $\begin{array}{l}\text { HORA } \\
\text { Inteio }\end{array}$ & $\begin{array}{l}\text { EXXPOSIC ION } \\
\text { TGraino }\end{array}$ & $\begin{array}{l}\text { ARENA DEFOSITADA } \\
\text { EN CADA TUBO PCR } \\
\text { BL VIEMIO } \\
\text { MB }\end{array}$ & $\begin{array}{l}\text { PORCENTAJE DEL } \\
\text { PESO TOTAL } \\
x^{4}\end{array}$ & $\begin{array}{l}\text { ALTURA SOBRE EL } \\
\text { SUELO DF LA TAR- } \\
\text { GENTE INFERIOR A } \\
\text { LA BOCA DEJ TUBO. }\end{array}$ \\
\hline 2 & 1510 & 1800 & 3.686 & 64.89 & 0.00 \\
\hline 2 & $"$ & $n$ & 1.262 . & 2222 & 2.12 \\
\hline 3 & " & $"$ & 472. & & 4.24 \\
\hline 4 & $"$ & $n$ & 176. & & 6.36 \\
\hline 5 & " & $"$ & 58. & & 8.48 \\
\hline 6 & " & $n$ & 19. & & 10.61 \\
\hline 7 & " & $"$ & 6. & & 12.73 \\
\hline 8 & " & $n$ & 2. & 12.90 & 14.85 \\
\hline & \multicolumn{2}{|c|}{ so total on 98.} & 5.681 . & 100,00 & \\
\hline
\end{tabular}




\section{MEDICIONES DE ARENA EOLICA EXTRAIDA DE LA PLAYA DE SANTA ROSA POR DEFLACION}

\section{AINEXO NO. 5}

Experimento IV
Experimento $V$

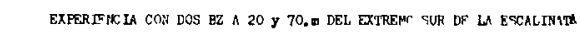

- Lugar playe senta roge

D - FrChA (10-58) Diec de Abril do 1958

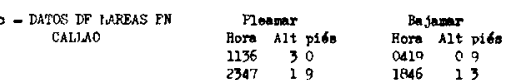

d - DISTANCIA DE LOS ARENINETROS A LA LINEA HVREDA DEZ OLEAJE O TE ALTA MAREA A' TNICIO $10 \mathrm{~m}$

- - VEIOCTDND PROREDTO DFI VIENTO OI 6 =

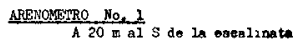

TUBO HORA EXFOSTCION ARENA DFPOSTTADA PORCENTAJE DEL ALTURA GOTRE EL

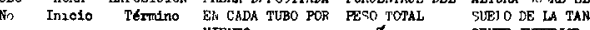

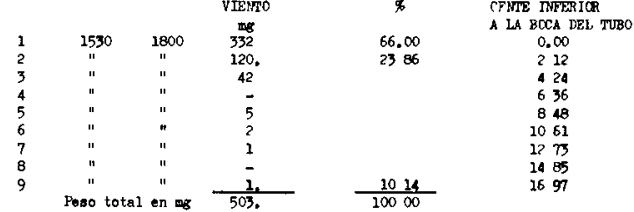

Taempo total de exposición 150 minutos

ARP' OMETRE NO, N

TOBO HORA EXPOSTCION ARFIF DEPOSTTADA FORCFITAJE DEL ALTURA COBRE EL

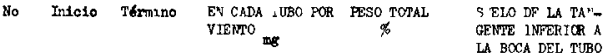

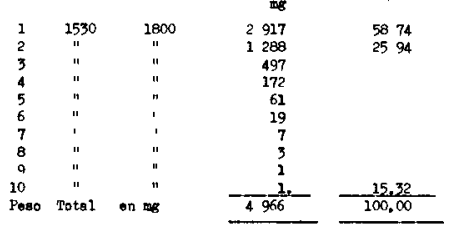

$\begin{array}{rl}0 & 00 \\ 2 & 12 \\ 4 & 24 \\ 6 & 36 \\ 8 & 48 \\ 10 & 61 \\ 12 & 73 \\ 14 & 85 \\ 1697 \\ 19,09\end{array}$

Trempo total do exposicion 150 mimutos

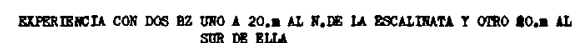

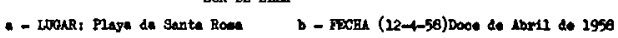

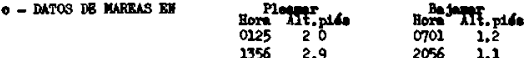

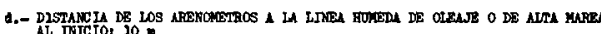

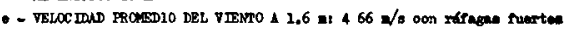

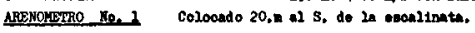

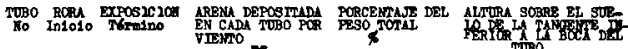

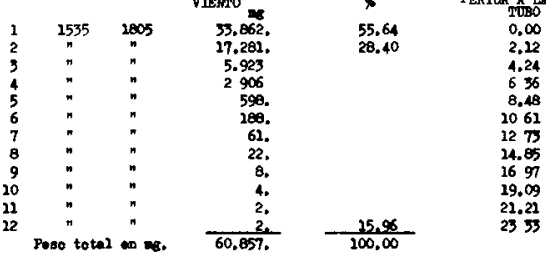

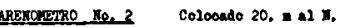

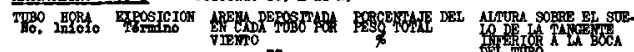

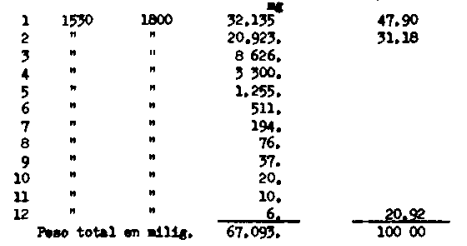

ANEXO NO. 6

Planos mostrando las áreas de captación

$A D=$ Diómetro interior del tubo de pruebo $=13 \mathrm{~mm}$

$A B=A^{\prime} B^{\prime}=$ Proyección verficol del eje menor de lo elipse de coptoción

$r e 01=A D \times \operatorname{sen} 45^{\circ}=13 \mathrm{~mm} \times 07071=919 \mathrm{~mm}$

Areo elipse de coptocián $=\frac{\pi}{4} \times 1$ moyor $\times$ menor $=07854 \times 13 \times 919$

Areo elipse de coptacián $=9383 \mathrm{~mm}^{2}= \pm 1 \mathrm{~cm}^{2}$

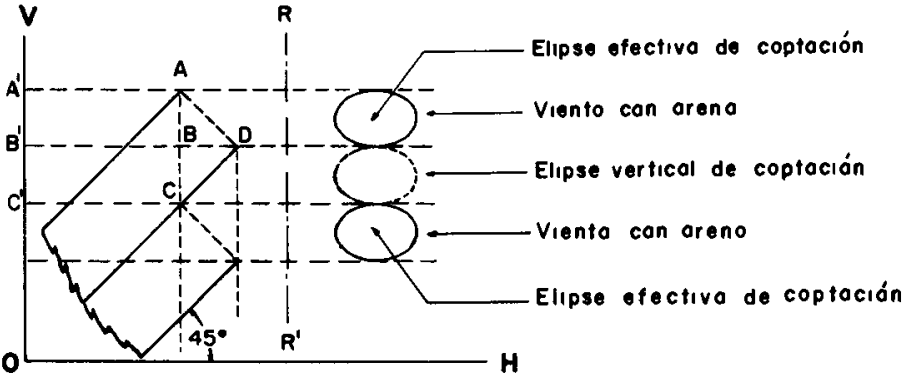

